Published in final edited form as:

Pflugers Arch. 2012 January ; 463(1): 139-160. doi:10.1007/s00424-011-1053-z.

\title{
Sleep and metabolic function
}

\author{
Lisa L. Morselli, \\ Department of Medicine, University of Chicago, Chicago, IL, USA
}

Aurore Guyon, and

INSERM/UCBL-U628, Physiologie intégrée du système d'éveil, Département de Médecine

Expérimentale, Faculté de Médecine, Université Claude Bernard Lyon 1, 8 avenue Rockefeller, 69373 Lyon Cedex 08, France

\author{
Karine Spiegel \\ INSERM/UCBL-U628, Physiologie intégrée du système d'éveil, Département de Médecine \\ Expérimentale, Faculté de Médecine, Université Claude Bernard Lyon 1, 8 avenue Rockefeller, \\ 69373 Lyon Cedex 08, France
}

\section{Abstract}

Evidence for the role of sleep on metabolic and endocrine function has been reported more than four decades ago. In the past 30 years, the prevalence of obesity and diabetes has greatly increased in industrialized countries, and self-imposed sleep curtailment, now very common, is starting to be recognized as a contributing factor, alongside with increased caloric intake and decreased physical activity. Furthermore, obstructive sleep apnea, a chronic condition characterized by recurrent upper airway obstruction leading to intermittent hypoxemia and sleep fragmentation, has also become highly prevalent as a consequence of the epidemic of obesity and has been shown to contribute, in a vicious circle, to the metabolic disturbances observed in obese patients. In this article, we summarize the current data supporting the role of sleep in the regulation of glucose homeostasis and the hormones involved in the regulation of appetite. We also review the results of the epidemiologic and laboratory studies that investigated the impact of sleep duration and quality on the risk of developing diabetes and obesity, as well as the mechanisms underlying this increased risk. Finally, we discuss how obstructive sleep apnea affects glucose metabolism and the beneficial impact of its treatment, the continuous positive airway pressure. In conclusion, the data available in the literature highlight the importance of getting enough good sleep for metabolic health.

\section{Keywords}

Sleep loss; Sleep apnea; Insulin resistance; Diabetes; Obesity

\section{Introduction}

The brain consumes up to two thirds of the circulating glucose [127]. Thus, it is not surprising that major changes in brain activity, such as those associated with sleep-wake and wake-sleep transitions, impact glucose metabolism. Evidence for a modulatory impact of sleep on metabolic and endocrine systems was first reported more than four decades ago. In particular, glucose tolerance, the 24-h pattern of release of insulin, and the counterregulatory hormones growth hormone $(\mathrm{GH})$ and cortisol, as well as of hormones involved in the

(c) Springer-Verlag 2011

K. Spiegel karine.spiegel@univ-lyon1.fr . 
regulation of appetite, such as leptin and ghrelin, are partly dependent on sleep timing, duration, and quality $[59,168,186]$. In this article, we will first summarize the current knowledge indicating that sleep modulates hormones involved in glucose control and appetite regulation. The data presented in this section were mostly obtained using total sleep deprivation paradigms. The second and third sections review the epidemiologic evidence that has rapidly accumulated over the last decade, as well as results of laboratory studies that experimentally enforced recurrent sleep restriction or disturbed sleep, to suggest that recurrent reduced sleep duration and/or quality are risk factors of obesity and diabetes. Results from the laboratory studies provide putative mechanisms involved in the relationship between lack of sleep and increased risk of metabolic diseases evidenced in epidemiologic studies. Finally, the last section summarizes the impact of OSA, a highly common sleep disorder, on glucose metabolism.

\section{Sleep modulates glucose regulation and hormones involved in appetite regulation}

\section{Glucose regulation and sleep}

Glucose is the primary source of energy for many tissues and, in normal circumstances, it is the only energy source in the brain. Unlike the liver and the muscles, which are able to store glucose in the form of glycogen, the brain depends entirely on glucose delivered via the circulation. Blood levels of glucose are therefore tightly regulated to avoid hypoglycemia and the associated impairment of the central nervous system and also to prevent hyperglycemia-induced tissue damage. Glucose homeostasis is controlled primarily by insulin, an anabolic hormone produced by the pancreas in response to rising levels of blood glucose, typically after eating. Several catabolic hormones [glucagon, catechol-amines, cortisol, and growth hormone (GH)] oppose the action of insulin; they are commonly referred to as counter-regulatory hormones. After carbohydrate ingestion, insulin rapidly promotes glucose uptake by tissues dependent on insulin to absorb glucose from the circulation, such as muscle and fat, and suppresses the release of glucose by the liver by stopping the conversion of glycogen to glucose. Thus, glucose homeostasis is critically dependent on the ability of pancreatic beta cell to release insulin both acutely (i.e., acute insulin response to glucose or beta cell responsiveness) and in a sustained fashion and on the ability of insulin to inhibit hepatic glucose production and promote glucose disposal by peripheral tissues [i.e., insulin sensitivity (SI)]. Reduced insulin sensitivity, or insulin resistance, occurs when higher levels of insulin are needed to reduce blood glucose levels following the administration of the same amount of exogenous glucose.

The regulation of energy homeostasis results from the interaction of sleep-wake homeostasis and circadian rhythmicity as well as the influence of environmental factors such as postural changes, stress, food intake, and exercise. In order to delineate the respective contributions of sleep and circadian rhythmicity on endocrine and metabolic functions, experimental strategies involving sleep deprivation during the night and sleep recovery during the day have been used $[151,152,187]$. Such protocols allow for the effects of time of day to be observed in the absence of sleep and the effects of sleep to be observed at an abnormal circadian time. Figure 1 shows, from top to bottom, the profiles of GH, cortisol, glucose, and insulin in healthy young men studied during a 53 -h period, including $8 \mathrm{~h}$ of nocturnal sleep followed by $28 \mathrm{~h}$ of continuous wakefulness and $8 \mathrm{~h}$ of daytime recovery sleep [151, 152, 187]. GH levels are increased during sleep, irrespective of the time at which sleep occurs, and they are markedly diminished during sleep deprivation. In fact, in healthy young men, a major $\mathrm{GH}$ pulse that accounts for roughly $70 \%$ of the daily production occurs shortly after sleep onset [188], in association with the first phase of slow wave sleep (SWS). The link between SWS and GH is quantitative, as a dose-response relationship between 
slow wave activity (SWA) and the amount of GH secreted has been evidenced in young and older men. Taken together, these results indicate that sleep-wake homeostasis is a major determinant of GH secretion $[59,168,186]$. The 24-h profile of cortisol comprises an early morning rise, declining levels during the daytime and a quiescent period centered around midnight. As shown in Fig. 1b, this profile is only modestly affected by the presence or absence of sleep. The 24-h periodicity of corticotropic activity is therefore primarily controlled by circadian rhythmicity. Nevertheless, wake-sleep and sleep-wake transitions are associated with inhibition and stimulation of cortisol levels, respectively $[59,168,186]$. As a result, the amplitude of the 24-h cortisol profile appears slightly dampened during extended wakefulness.

The mean profiles of blood levels of glucose and insulin are shown in Fig. 1c, d [187]. Both nocturnal and daytime sleeps were associated with a marked decrease in glucose tolerance, reflected by increased glucose levels. The rise in glucose levels was followed by increased insulin levels and peaked during the middle of the sleep period. A glucose and insulin elevation of roughly half the amplitude of the one observed during nocturnal sleep was apparent during the night of sleep deprivation, indicating that circadian-dependent processes also modulate glucose regulation. In this experiment, caloric intake consisted exclusively in a glucose infusion at a constant rate to avoid the confounding effects of feeding and fasting. Other studies have used continuous enteral nutrition and obtained similar results $[151,152]$. Under these experimental conditions, the major underlying cause of the decrease in glucose tolerance is decreased glucose utilization. Both the brain and peripheral tissues use less glucose during early sleep. SWS, which is particularly abundant at the beginning of the sleep period, has been shown to result in a 30-40\% decrease in cerebral glucose metabolism relative to waking or rapid eye movement (REM) sleep [12]. A recently published study in rats [43] reported an increase in ATP levels in wake-active brain regions at the beginning of the sleep period, in tight association with SWA. Although these results have been challenged by other authors $[64,70,210,211]$, they are in line with earlier reports of decreased brain energy use during non-REM (NREM) sleep. Muscle relaxation and the rapid hyperglycemic effects of the sleep-onset GH pulse account for the remaining fall in glucose uptake during early sleep [103]. During the later part of the night, glucose levels decrease toward morning values, reflecting improvement of glucose tolerance. This progressive increase in glucose uptake is likely to reflect the replacement of SWS by REM sleep and the increased insulin sensitivity due to a delayed effect of low cortisol levels during the evening and early part of the night [129]. Thus, glucose regulation is markedly influenced by circadian rhythmicity and sleep, and these effects could be partially mediated by cortisol and GH.

Type 2 diabetes is a complex metabolic disorder that involves insulin resistance, impaired insulin secretion, and increased glucose production [37, 79]. Early stages of type 2 diabetes are characterized by insulin resistance causing excessive post-prandial hyperglycaemia. This is followed by a deteriorating first-phase insulin response to increased blood glucose concentrations. The prevalence of type 2 diabetes is increasing worldwide, reaching pandemic proportions: The number of adults aged 25 years or older with diabetes has more than doubled over nearly three decades and is currently approaching 350 million [34]. Type 2 diabetes is influenced by age, ethnicity, and genetic susceptibility. Recent genome-wide association studies have identified genetic loci that predispose to glucose intolerance [128]. Whether diabetes develops is then influenced by environmental factors, some clearly understood, others less so. If it is obvious that our modern lifestyle of physical inactivity and increased food intake is involved in the growing prevalence of type 2 diabetes worldwide, various other behavioral and environmental factors are likely to contribute to the progression of this disease. The next two sections summarize the epidemiologic and experimental evidence that has recently accumulated to suggest that sleep loss and poor sleep quality may be such contributors. Voluntary sleep curtailment has, indeed, become an increasingly 
common behavior in all age groups over the past several decades, most likely reflecting the demands and opportunities of modern society [75, 114]. In addition, the prevalence of sleep disorders, particularly obstructive sleep apnea (OSA), has greatly increased, although they often remain undiagnosed.

\section{Appetite regulation and sleep}

The regulation of food intake involves "hunger" and "satiety" signals, secreted by the hypothalamus as well as by peripheral organs, mainly the adipose tissue and the gastrointestinal tract. Hunger signals, such as ghrelin and neuropeptide $\mathrm{Y}$, often drive the initiation of a meal, while satiety peptides, like glucagon-like peptide (GLP-1), peptide YY (PYY), cholecystokinin (CCK), insulin, and leptin terminate consumption. The regulation of food intake also involves factors such as food reward, environmental cues, and cognitive factors, processed in cortico-limbic structures.

Feeding and sleeping are mutually exclusive: They are both time-consuming and occur in cyclic patterns. Although everyone has experienced somnolence after a large meal, the association between feeding and sleeping only started to be examined in the late 1970s. In rodents, food shortage or starvation results in decreased sleep [35], and, conversely, total sleep deprivation leads to marked hyperphagia [133]. Evidence has accumulated over the past 13 years to indicate that the orexin system plays a central role in this vital interaction between feeding and arousal. Orexins (also called hypocretins), two distinct peptides (orexin A and B) synthesized by neurons in the lateral hypothalamus ( $\mathrm{LH}$ ), stimulate not only arousal but also feeding (see $[136,139]$ for review). Hypocretin-containing neurons in the lateral hypothalamus project directly to the locus coeruleus and to other brainstem and hypothalamic arousal areas. These neurons also interact with the leptin-responsive neuronal network involved in balancing food intake and energy expenditure (EE). The orexin system has been shown to be overactive when sleep deprivation is behaviorally enforced in rats, dogs, and squirrel monkeys [49, 212, 216], most likely to maintain wakefulness against the increased sleep pressure. A profound impact of sleep loss and/or poor sleep quality on appetite regulation should therefore be expected.

Sleep modulates the $24 \mathrm{~h}$ pattern of secretion of two key hormones involved in energy balance regulation, i.e., leptin and ghrelin [1, 193]. Circulating leptin is derived from the adipocytes, while circulating ghrelin is derived predominantly from the stomach [191]. Leptin inhibits hunger and food intake, increases EE, and promotes fat utilization [1, 193]. Fasting and feeding lowers and elevates leptin levels, respectively [25, 84]. In humans, under normal feeding circumstances, the 24-h leptin profile shows increasing levels during the daytime that culminate in a nocturnal maximum [148]. The gradual increase of leptin over the course of the day reflects the impact of meal intake. A study using an abrupt 8-h shift of bedtimes and continuous enteral nutrition to eliminate the impact of meal intake demonstrated that both sleep and circadian rhythmicity elevate leptin levels [153]. The stimulating impact of sleep on leptin has also been evidenced in a subsequent study that showed decreased amplitude of the leptin diurnal variation during prolonged total sleep deprivation [107]. The increased leptin levels during nocturnal sleep, a result of the combined influence of sleep and circadian rhythmicity, may facilitate the maintenance of prolonged fasting. The relationship between leptin and sleep appears to be bidirectional; systemic administration of leptin to normally fed rats increases SWS and decreases REM sleep [155], and leptin deficiency in ob/ob mice disrupts sleep architecture and impairs sleep consolidation [90].

In contrast to leptin, ghrelin stimulates hunger and food intake, reduces EE, and promotes the retention of fat $[56,58,92,191]$. While ghrelin acylation, under the control of the enzyme ghrelin- $O$-acyl-transferase (GOAT), is essential for its orexigenic effects [92, 191], 
most of the physiology of human ghrelin has been based on the measurement of blood levels of total ghrelin, which mainly reflect unacylated ghrelin levels. In humans, ghrelin levels decrease after food ingestion in proportion to caloric load and rise before initiation of the next meal, paralleling the increase in hunger [17, 33]. As early as 2001 [32], studies involving frequent sampling across the 24-h cycle observed a nocturnal elevation of total ghrelin levels with peak values during the sleep period and declining levels toward the morning. All $[95,166]$ but one [3] of the studies that have attempted to characterize the overnight profiles of acylated ghrelin in relation to unacylated ghrelin confirmed the increased nocturnal elevation in total ghrelin and demonstrated a concomitant increase in acylated ghrelin. To date, the significance of this rise and fall of ghrelin during the overnight fast remains unknown, though it may contribute to the well-established reduced EE associated with sleep [10, 53, 78, 207]. Only two studies directly examined the role of sleep on nocturnal ghrelin release in humans: one found that sleep deprivation inhibited total ghrelin levels [44]; the other study found that sleep deprivation inhibited total ghrelin at the beginning of the night and stimulated total ghrelin in the second half of the night [5]. An inhibitory influence of sleep deprivation would contradict animal studies linking the promotion of feeding with the maintenance of wakefulness $[9,172,173]$. More in line with an inhibitory influence of sleep on ghrelin, a recent study reported that the nocturnal elevation of ghrelin is likely to reflect the post-dinner rebound curbed by an inhibitory effect of sleep [166]. This latter study also found that the ratio acylated ghrelin/total ghrelin was lower during sleep than during wake, suggesting that GOAT activity may be decreased during sleep, consistent with a reduction of orexigenic signal. These findings support an inhibitory effect of sleep on ghrelin, consistent with the association between sleeping and fasting and, conversely, between feeding and arousal. In addition to its orexigenic effects, ghrelin has also been identified as a potent GH secretagogue based on exogenous administration [56], and a correlation between GH andghrelin levels has been reported in some, but not all, studies [3, 48, 85, 106, 112, 113, 149]. A large body of evidence supports the hypothesis that ghrelin acts on GH secretion, at least in part, via a stimulation of GHRH [39, 50, 192]: A positive interaction between central ghrelinergic activity and sleep, in particular SWS, should therefore be expected. However, as mentioned above, the interaction between ghrelin and sleep regulation is still poorly understood, as animal and human studies yielded inconsistent results.

Peptide YY (PYY) is another gut peptide involved in the regulation of food intake. In contrast to ghrelin, PYY inhibits appetite. Preliminary data obtained in humans observed that ghrelin and PYY levels show opposite variations over the 24-hspan [163]. The respective contribution of sleep upon the $24 \mathrm{~h}$ PYY profile has not been assessed.

Taken together, these data suggest that sleep loss and/or poor sleep quality is likely to have a profound impact on appetite regulation.

\section{Short sleep and/or poor sleep loss as risk factors of diabetes}

\section{Epidemiologic evidence}

Several large cross-sectional studies (reviewed in detail in $[82,178]$ ) have reported an association between short ( $\leq 5$ or $\leq 6 \mathrm{~h}$ per night) and/or poor sleep and increased prevalence of diabetes or impaired glucose tolerance, after controlling for age, body mass index (BMI), and various other confounders. To note, recent national surveys indicate that $16 \%$ of working Americans and $17 \%$ of French adults aged $25-45$ years sleep $<6 \mathrm{~h}$ on a typical weeknight $[75,114]$. Some studies also reported an association between self-reported long sleep duration ( $\geq 8$ or $\geq 9 \mathrm{~h}$ per night) and increased risk of diabetes [82]. These crosssectional studies cannot address the direction of causality; having diabetes could impair sleep, or, conversely, as the laboratory studies presented below suggest, poor or insufficient 
sleep may increase the risk of diabetes. In contrast, prospective studies that have assessed sleep characteristics at baseline and incidence of diabetes over a follow-up period provide some indication regarding the direction of causality. Nine studies have examined the impact of self-reported sleep duration, and six studies have addressed the impact of sleep quality as determined by self-report of sleep problems such as difficulty initiating or maintaining sleep or use of sleeping pills (reviewed in [80]). None of these studies has involved objective measures of sleep. Short sleep duration (mostly $\leq 5 \mathrm{and} /$ or $\leq 6 \mathrm{~h}$ ) was found to predict a higher incidence of diabetes in seven of the nines studies, while poor sleep quality was associated with an increased risk of diabetes in five of the six studies [80]. Two studies reported increased odds of diabetes associated with longer sleep durations ( $\geq 9 \mathrm{~h})$. One recent metaanalysis including ten prospective studies with a follow-up of $>3$ years concluded that sleep duration and sleep disturbances consistently predicted the risk of incident type 2 diabetes. The pooled relative risk (RR) was 1.28 (95\% CI, 1.03-1.60; $p=0.024)$ for short sleep $(\leq 5-6 /$ night), 1.48 (95\% CI, 1.13-1.96, $p=0.005$ ) for long sleep ( $>8-9 \mathrm{~h} /$ night), 1.57 (95\% CI, $1.25-1.97, p<0.0001$ ) for difficulty initiating sleep, and 1.84 (95\% CI, 1.39-2.43, $p<0.0001$ ) for difficulty maintaining sleep [19]. Thus, taken together, prospective epidemiologic studies strongly suggest that subjective short or long sleep duration and sleep disturbances predict the development of diabetes. Future prospective epidemiologic studies need to include objective measures of sleep in order to assess the contribution of sleep quality in the relationship between short or long sleep and increased risk of diabetes. For instance, one may spend more time in bed in order to compensate for poor sleep. The extent to which the extended wake resulting from sleep curtailment is spent in activities deleterious for energy homeostasis should also be examined [102]. However, well-controlled experimental studies suggest that the lack of sleep per se is likely to negatively impact on glucose metabolism.

\section{Evidence from experimental laboratory studies}

Total sleep deprivation studies-The impact of sleep loss on glucose metabolism was first evaluated using total sleep deprivation (TSD) paradigms. The results of seven studies, comprising 24-126 h of forced wakefulness, are available in literature and are reported in Table 1. Of these seven studies, six reported a deleterious impact of TSD on at least one aspect of glucose metabolism. Increased fasting glucose was reported after $120 \mathrm{~h}$ of TSD [200] but not after 72-126 h [86] or one single night of TSD [5, 143, 195, 204], suggesting that fasting glucose may be sensitive to only severe TSD. Four studies assessed glucose tolerance by analyzing the glucose response to an oral glucose tolerance test (OGTT) or to a standardized breakfast $[5,86,195,204]$. Glucose tolerance was found to be altered in two studies, i.e., after 72-126 h of TSD [86] and after $24 \mathrm{~h}$ of TSD [5]. Normal glucose tolerance is achieved when the beta cells are able to secrete appropriate amounts of insulin in a timely manner in combination with adequate hepatic and muscular insulin sensitivity (SI) [137]. Kuhn et al. [86] did not report SI and beta cell function. In the study by Benedict et al. [5], the decreased glucose tolerance in a state of sleep debt was the consequence of reduced SI combined to beta-cell dysfunction since insulin levels were not affected by the presence or absence of sleep. Of the two studies that found no effect of sleep loss on glucose tolerance, one reported that glucose tolerance after $60 \mathrm{~h}$ of TSD was preserved despite decreased SI because of a compensatory increase in insulin secretion [195]. The other study reported similar glucose tolerance after baseline sleep, after one night of TSD, and after one night of sleep recovery following a 4-h daytime nap [204]. However, postprandial insulin was increased after sleep recovery, suggestive of decreased insulin sensitivity. The authors hypothesize that these unexpected results could be due to a delayed effect of sleep deprivation not counterbalanced by a single night of recovery sleep. Thus, of the three studies that assessed SI after a glucose load, two found reduced SI after sleep loss [5, 195] and one found reduced SI after recovery sleep [204]. Evidence for a decrease in SI after TSD was also reported in a study that evaluated SI by insulin suppression test modified with 
octreotide [57]. By contrast, Schmid et al. found no alteration of SI, assessed by stepwise hypoglycemic clamp, after one night of sleep deprivation. In this latter study, somewhat unexpectedly, decreased baseline glucagon levels and enhanced relative glucagon response were observed after TSD, compared to a 7-h night, indicating a modified pancreatic alphacell function [143].

Partial sleep deprivation studies-Partial sleep deprivation (PSD) studies better reflect the habits of our current society, in which voluntary sleep curtailment has become increasingly common. In the first study looking at the effect of sleep debt on metabolic and endocrine function, 11 young men underwent a restriction of their time in bed to $4 \mathrm{~h}$ for five to six nights; carbohydrate metabolism, 24-h profiles of the counter-regulatory hormones cortisol and GH, and cardiac sympathovagal balance were assessed [159-161]. These results were compared with measurements taken at the end of a sleep-recovery period with 12-h bedtimes for five to six nights. An intravenous glucose tolerance test (ivGTT) and a highcarbohydrate breakfast showed that glucose tolerance was lower in the sleep-debt condition than in the fully rested condition [159]. The left panel of Fig. 2 shows a re-analysis of the data from the ivGTT. Glucose tolerance during this ivGTT was decreased by more than $40 \%$ when the subjects were in a state of sleep debt and reached values typical for older adults with impaired glucose tolerance [54]. The ivGTT is a validated tool that also provides assessments of SI, pancreatic beta-cell responsiveness (referred to as "acute insulin response to glucose", AIRg), and glucose effectiveness (SG), a measure of non-insulin-dependent glucose disposal [7]. SG, AIRg, and SI were decreased by $~ 25 \%$ in the state of sleep debt. Considering that the brain is a major user of glucose, the decrease in SG is likely to reflect decreased brain glucose utilization, as shown by PET studies [183]. The disposition index (DI), the product of AIRg and SI, which provides an estimate of beta-cell function relative to the prevailing level of insulin resistance, has been shown to be a validated marker of diabetes risk [96, 123]. In healthy subjects, insulin resistance is accompanied by compensatory hyperinsulinemia, which in turn maintains a constant DI. Compared to the fully rested state, DI was decreased by $50 \%$ in the state of sleep debt. Furthermore, three of the 11 subjects had DI values <1000, indicating a high risk of diabetes [213]. Increased evening cortisol concentrations, extended duration of elevated GH concentrations during the waking period, and increased cardiac sympathovagal balance were also observed in the sleep loss condition [159-161], all of which could underlie the clinically significant deleterious impact of recurrent sleep restriction on glucose metabolism. Sympathetic activation inhibits and para-sympathetic activation stimulates insulin release; the lack of compensatory hyperinsulinemia in response to the reduced SI associated with sleep loss may therefore be related to an alteration of the autonomic regulation of the beta cells. In addition, changes in counterregulatory hormones and elevated ghrelin levels, which in the next section will be shown to also increase with sleep loss, favor glucose intolerance and hyperinsulinemia [130, 189].

A recent study in 20 healthy lean and overweight men confirmed and extended these findings. Buxton et al. [16] assessed glucose metabolism by iv GTT and euglycemichyperinsulinemic clamp after seven to eight nights of 10-h bedtime and after six to seven nights of 4-h bedtime. The results of the ivGTT are presented in the second panel from the left of Fig. 2. Recurrent reduced time in bed was associated with a decrease in SI that was not compensated for by an increase in insulin secretion. As a result of these alterations, similarly to the previous study, glucose tolerance, and the DI were reduced after sleep curtailment. Buxton et al. confirmed the decrease in SI derived from the ivGTT by hyperinsulinemic euglycemic clamp, considered to be the gold standard method for SI determination [16]. 
As of today, a total of 11 studies have evaluated the effects of PSD on glucose metabolism. The main results of these studies that involved young and middle-aged men and women undergoing various durations of PSD are summarized in Table 1. An impairment of glucose tolerance was observed in six studies, after an average of $5 \mathrm{~h}$ in bed for six consecutive nights compared to a rested condition [16, 91, 115, 147, 159, 164]. SI, assessed in five of these six studies, was consistently found to be decreased [16, 91, 115, 147, 159]. Evidence of beta-cell dysfunction was found for all but one [147] of these studies. Two other studies $[41,194]$ reported only a decrease in SI, with apparent preservation of glucose tolerance. Of note, two groups $[41,147]$ observed that sleep loss was associated with increased levels of free fatty acids, which have been implicated in the pathogenesis of insulin resistance [140]. Conversely, three studies [11, 145, 217] found no alterations in measures of glucose metabolism. Zielinski et al. [217] assessed the effect of semi-chronic (8 weeks) sleep curtailment on glucose tolerance in self-reported older long sleepers $(\geq 8.5 \mathrm{~h} / \mathrm{night})$, compared to a control group. However, the self-reported long sleep duration contrasted with the $\sim 7.5 \mathrm{~h}$ of sleep assessed by actigraphy at baseline, and bedtime restriction resulted in total sleep time being decreased by only $1 \mathrm{~h}$ on average. Furthermore, sleep duration was also decreased in the control group, and the final difference in total sleep time between the two groups was only approximately $16 \mathrm{~min}$ [81]. The negative findings regarding glucose tolerance are therefore not unexpected. Bosy-Westphal et al. [11] are the only group who focused exclusively on pre-menopausal women, who may be more resistant to the alterations in glucose metabolism induced by sleep deprivation. Indeed, a recent meta-analysis of prospective studies evaluating the relationship of habitual sleep disturbances to the development of type 2 diabetes found a lower relative risk of incident diabetes for female short-sleepers compared to male short-sleepers [19]. Moreover, Bosy-Westphal et al. exposed their volunteers to a progressive and moderate sleep restriction $(5.75 \mathrm{~h}$ in bed on average) over four nights, which may not be sufficient to elicit clear-cut impairments in glucose metabolism. A third study, in which subjects underwent a stepwise hypoglycemic clamp, yielded negative results regarding the impact of sleep restriction on SI [145]; a decrease in glucagon levels both at baseline and during insulin-induced hypoglycemia was observed, which indicates a reduced alpha-cell function. The same authors [147] later reported a decreased glucagon response to an ad libitum breakfast compared to the rested condition, suggesting again a reduced function of the pancreatic alpha cells. Such an alteration would arguably not contribute to the impairment in glucose metabolism. However, it is difficult to extrapolate what would happen in a chronic sleep deprivation setting, since glucagon secretion is stimulated by the sympathetic nervous system that has been shown to be stimulated under semi-chronic sleep deprivation conditions [115, 161]. Further studies are needed to investigate this aspect of glucose metabolism during PSD.

To summarize, impaired SI was reported in seven of 11 studies, and beta-cell dysfunction was observed in five of 11; the average duration of time in bed and sleep deprivation period were comparable in both cases. To note, studies reporting negative results have used a more moderate sleep restriction paradigm [11,217] or methods of SI quantification with lower sensitivity [145]. Evidence is also emerging about altered glucagon secretion, but further studies are necessary to assess the exact effect of partial sleep deprivation on alpha-cell function.

Poor sleep quality and glucose regulation-Two studies have demonstrated that poor sleep quality, independently of sleep duration, impairs glucose regulation in healthy young adults $[167,176]$. The first study selectively suppressed SWS in healthy young adults during three consecutive nights [176]. The second study fragmented sleep across all sleep stages during two consecutive nights [167]. Both studies assessed glucose metabolism using an ivGTT and involved a level of sleep fragmentation of approximately 30 events per hour on each night, i.e., a degree of sleep fragmentation typical of moderate to severe OSA. 
Results from the ivGTTs of these two studies are displayed on the right two panels of Fig. 2. After three nights of SWS suppression, SI was decreased by 25\%, reaching the level reported in older adults and in populations at high risk of diabetes [6]. The decrease in SI following experimental reduction of SWS was not compensated for by an increase in insulin release, as AIRg remained virtually unchanged. Consequently, the DI was $~ 20 \%$ lower after SWS suppression. Consistent with an increased diabetes risk, glucose tolerance was reduced by $\sim 23 \%$ reaching the range typical of older adults with impaired glucose tolerance [176]. Fragmentation across all sleep stages for two nights resulted in a similar 25\% decrease in SI. In this latter study, however, the DI was not affected by the sleep fragmentation since an increase in insulin release was able to compensate the decrease in SI. Glucose effectiveness was reduced by $21 \%$. In the study by Tasali et al. [176], the amount of SWS was decreased by nearly $90 \%$. Random sleep fragmentation mainly resulted in a $70 \%$ decrease in SWS with a minimal impact on REM sleep [167]. Importantly, in the study by Tasali et al., the changes in the two main determinants of glucose tolerance, i.e., SI and AIRg, were correlated with the changes in SWS after the intervention. Physiological temporal correlates of SWS such as decreased brain glucose utilization, stimulation of GH release, inhibition of cortisol secretion, decreased sympathetic nervous activity, and increased vagal tone are likely to affect total body glucose homeostasis. Reduced or absent SWS is very common, as it occurs in normal aging and in individuals suffering from OSA. Both aging and OSA are recognized risk factors for decreased glucose tolerance and increased diabetes risk. These laboratory findings demonstrate unequivocally that disruptions in sleep quality do adversely affect glucose regulation.

\section{Short sleep as risk factor of obesity}

\section{Epidemiologic evidence}

An ever-growing number of cross-sectional and case-control epidemiological studies ( 65 by 2009 [80]) have provided evidence of an independent link between short sleep (generally $<6$ $\mathrm{h}$ per night in adults) and the risk of obesity [82, 100, 124]. The association between short sleep and increased BMI is particularly strong and consistent in children [82, 100, 124]. Studies in adults are less consistent and often show a U-shaped relationship between sleep duration and BMI. Two meta-analyses including more than 600,000 adults and 30,000 children worldwide have quantified the link between short sleep and obesity risk. In the first study, the pooled odds ratio (OR) linking short sleep to obesity was 1.89 (95\% CI, 1.462.43; $p<0.0001)$ in children and 1.55 (95\% CI, 1.43-1.68; $p<0.0001)$ in adults [18]. The second study reported an OR of 1.58 (95\% CI, 1.26-1.98) in children with short sleep duration and an OR of 1.92 (95\% CI, 1.15-3.2) in children with the shortest sleep duration, suggesting a dose-response relationship between sleep duration increased risk of obesity [23].

Of the 28 longitudinal studies that examined the impact of short sleep on obesity risk in children and adults, 22 reported that short sleep is associated with an increased risk of weight gain or development of obesity and/or increased fat mass a few years later (reviewed in [80]; additional references: [8, 21, 38, 89, 94, 97, 101, 105, 120, 150, 202]). This pattern is particularly consistent in pediatric populations (all 12 studies had positive findings; reviewed in [80]; additional references: [21, 38, 89, 150]). Importantly, the only pediatric prospective study that obtained concomitant objective measurements of sleep, weight, and body composition demonstrated that the increased weight gain in children sleeping less was the result of selective increased fat deposition [21]. U- or L-shaped associations were reported in some adult prospective studies (reviewed in [80]; additional studies: [97, 202]); hence, the relationship between longer sleep and BMI is conflicting in adults and inexistent in children. 
Thus, overall, the impact of reduced sleep duration on obesity risk is particularly clear in pediatric populations, probably because physiological and behavioral mechanisms responsible for this association are stronger in younger ages. Another explanation has recently been suggested: It is possible that weight is not gained linearly over the course of the short sleeping period. As a consequence, "in order for short sleep to predict any physiological or behavioral change, the longitudinal time frame examined would need to start prior to or at the beginning of the short sleep transition for each participant" [98], which is less likely to be the case with older ages.

To note, one prospective study in adults reported a bidirectional relationship between short sleep and obesity; not only did short sleep predict weight gain a few years later [67], but body weight or obesity also predicted short sleep duration on a later occasion. In addition, a large scale study [198] concluded that self-reported short sleep in obese adults may be a surrogate marker of subjective sleep disturbance [196]. Taken together, these results suggest the existence of a "vicious circle" where short sleep may initially promote weight gain, and the resulting excess adiposity would then induce sleep disturbances, with a further decrease in total sleep time. Such phenomenon is observed for other weight promoting behaviors, notably physical inactivity and overeating, both of which are reinforced by weight gain [158]. Future prospective studies need to determine whether short sleep in obese individuals is the result of bedtime curtailment or is due to the presence of a sleep disorder.

Critics have questioned the relevance of this link by putting forward the weakness of the association [74]. However, this may be the consequence, at least in part, of measurements errors since both sleep and weight assessments were based on self-reports in nearly all epidemiologic studies [119]. In support of this hypothesis, four studies that performed objective measurements reported a much stronger cross-sectional association than other studies of similar cross-sectional design but using self-reported data [63, 125, 182, 190]. It has also been argued that these epidemiological findings are of questionable clinical concern: "the worst case for weight gain that could be attributed to short sleep over a year is $<2.0 \mathrm{~kg}$ " [74]. However, even modest increases in weight have been shown to have significant implications for long-term adiposity-related metabolic dysfunction, diabetes, cardiovascular disease, and cancer [28, 46, 135, 208]. Studies are warranted to determine if getting enough good sleep is an efficient intervention for weight maintenance and/or weight loss. Such a study is currently under progress [27].

The following section presents results from experimental studies that have been able to suggest putative pathways linking short sleep to excess weight.

\section{Evidence from experimental laboratory studies}

Sleep duration and appetite regulation-One pathway that may link short sleep to excess weight is increased caloric intake in short sleepers. The following sections will present results from laboratory studies that have used total or partial sleep deprivation to explore the effects of sleep loss on subjective feelings of hunger, hormones involved in the control of appetite, caloric intake, and weight gain.

Total sleep deprivation studies: Very few studies have evaluated the impact of TSD on subsequent levels of hormones involved in appetite regulation and subjective feelings of hunger. Early studies of total or rapid eye movement sleep deprivation anecdotally reported increased feelings of hunger in some, but not all, subjects. Anecdotal evidence for an increase in food intake in subjects confined to the laboratory and permitted ad libitum access to food during 3 days of TSD wasreportedin1997[40]. More recently, two studies [5, 143] reported that a night of TSD resulted in increased subjective hunger the following morning. Accordingly, in the study by Benedict et al., ghrelin was higher in the second half of the 
night compared to a night of normal sleep, whereas nighttime leptin levels were unchanged. Conversely, no impact of TSD was evidenced in another recent study that also reported reduced amplitude of the 24-h leptin diurnal variation due to increased daytime leptin levels [126]. In view of the anorexinergic effect of leptin, these elevated leptin levels are not consistent with the increased hunger reported in previous studies.

Partial sleep deprivation studies: An increasing number of studies have attempted to delineate the impact of partial sleep deprivation on food intake regulation. Table 2 summarizes the results of these studies. The first study that simultaneously assessed the impact of sleep restriction on subjective feelings of hunger and hormones involved in the regulation of appetite was published in 2004 [162]. In this randomized cross-over design study, the daytime profiles of leptin and ghrelin were assessed in young normal-weight men after two nights of $4 \mathrm{~h}$ in bed vs. two nights of $10 \mathrm{~h}$ in bed, while the subjects completed validated scales for hunger and appetite for various food categories [162]. Leptin decreased by $18 \%$, while ghrelin increased by $28 \%$, and the ghrelin/leptin ratio increased by more than $70 \%$ when sleep was restricted (Fig. 3). The state of sleep loss also resulted in a $23 \%$ increase in hunger and in a 33\% increase in appetite for nutrients with high carbohydrate content. Seventy percent of the variance in increased hunger was explained by the increase in ghrelin/leptin ratio [162] (Fig. 3). Importantly, these differences in appetite regulation occurred despite identical amounts of caloric intake, similar sedentary conditions, and stable weight. By comparison, 3 days of underfeeding by approximately $900 \mathrm{cal} /$ day in healthy lean volunteers resulted in a $22 \%$ decrease of leptin levels [25]; these results highlight the functional significance of the decrease in leptin observed with sleep loss.

Were the increase in hunger observed during sleep restriction to translate into a commensurate increase in food intake, weight gain would occur over time. In accordance with this hypothesis, of the seven studies that assessed food intake during sleep restriction, six observed increased caloric consumption (Table 2). One night of $4 \mathrm{~h}$ in bed, in comparison with one night of $8 \mathrm{~h}$ in bed, resulted in a $22 \%$ increase in caloric intake during the subsequent day in healthy young men [14]. When young women were exposed to an ad libitum diet during two bedtime conditions, i.e., four nights of $\sim 5.5 \mathrm{~h}$ of sleep vs. two nights of $\sim 9 \mathrm{~h}$ of sleep, a $20 \%$ increase in self-reported food consumption was observed during sleep restriction [11]. In overweight middle-aged adults, increased consumption of calories from snacks with higher carbohydrate content was observed after 2 weeks of sleep restriction $(-1.5 \mathrm{~h} / \mathrm{night})$ in comparison to after 2 weeks of sleep extension $(+1.5 \mathrm{~h} / \mathrm{night})$, while energy intake from meal and total energy intake were unaffected by bedtime condition [116]. To note, each 2-week period was conducted in a setting of ad libitum access to palatable food. Since food intake is critically dependent on the amount and palatability of food provided to the subject [132], the subjects overate (>3,400 calories daily) in each bedtime condition, which may have masked the impact of sleep duration on total energy intake. Recently, in a crossover study, the food intake of middle-aged lean and overweight men and women was measured after five nights of $4 \mathrm{~h}$ bedtimes and after five nights of $9 \mathrm{~h}$ bedtimes. The volunteers ate $\sim 300 \mathrm{kcal} /$ day more, mostly from fat, notably saturated fat, during short sleep [170]. Importantly, in the latter two studies, EE measured with the gold standard doubly labeled water method did not differ between study conditions, therefore suggesting that the increase in food consumption most often associated with sleep loss is not related to a comparable rise in energy needs and would eventually result in a positive energy balance. Similar preliminary data have been obtained in two other studies that assessed caloric intake during an ad libitum buffet [104, 178]. Young normal weight men and women increased their caloric intake by $14 \%$, especially carbohydrate-rich nutrients, after four nights of $4.5 \mathrm{~h}$ in bed, compared to after four nights of $8.5 \mathrm{~h}$ in bed [178], and middle-aged obese subjects submitted to four to five nights of restriction or extension of their habitual sleep schedule by $2-3 \mathrm{~h} /$ night ate $15 \%$ more calories in the bedtime restriction condition 
[104]. The sole study that did not report any change in caloric intake after sleep loss proposed highly palatable food ad libitum $1 \mathrm{~h}$ after awakening after two nights of $4 \mathrm{~h}$ and after two nights of $8 \mathrm{~h}$ sleep. Again, this unlimited availability of palatable food resulted in overeating ( $+60 \%$ regardless of the bedtime condition) and may have masked the impact of sleep loss on food consumption [146]. Another methodological difference may contribute to the lack of effect of sleep loss on food intake in this study. In order to minimize the impact of the manipulation of sleep duration on the circadian system, most of the studies kept the center of the sleep period constant, therefore linking sleep restriction to an earlier awakening. In contrast, Schmidt et al. awakened the subjects at the same time in both bedtime conditions. In this latter setting, the subjects may be less prone to eat more than in the other studies where sleep restriction was associated with more time awake before caloric testing. Taken together, these results suggest that sleep loss can stimulate food intake with an excess of $>250 \mathrm{kcal} / \mathrm{day}$. Such an increase is highly meaningful as the amount of positive energy storage needed to explain the obesity epidemic is $\sim 50 \mathrm{kcal} /$ day [73]. Results regarding subjective feelings of hunger seem less consistent, as only five studies $[14,99$, $117,144,162]$ ofthe $11[11,14,99,117,122,144-146,162,170,194]$ that examined the effect of reduced sleep duration on hunger reported positive effects. However, if we exclude studies that allowed hunger to be satisfied by increased consumption of uncontrolled food availability, five of nine studies reported positive effects. Of note, the study of St-Onge et al. reported an increase of $\sim 300 \mathrm{kcal} / \mathrm{day}$ after 5 days of $4 \mathrm{~h}$ bedtimes, although there was no clear effect of sleep duration on subjective feelings of hunger and appetite on the previous day $[11,170]$, suggesting that subjective assessments are unreliable.

The effect of sleep loss on weight was examined in two studies that allowed ad libitum access to food during recurrent sleep restriction $[11,116]$. Inconsistent results were obtained. Bosy-Westphal et al. reported a weight gain of $0.4 \mathrm{~kg}$ in a group of freely living lean, overweight, and obese women after four nights of $\sim 5.5 \mathrm{~h}$ of sleep in comparison to two nights of $\sim 9 \mathrm{~h}$ of sleep [11]. By contrast, Nedeltcheva et al. observed similar weight at the end of each 14-day period of sleep extension or sleep restriction in overweight men and women exposed to unlimited palatable food in a laboratory setting. Consistent with the fact that overeating usually occurs when unlimited palatable food is available [132], the subjects overate and gained $\sim 2 \mathrm{~kg}$ in each sleep condition [116]. Finally, a recent study examined if sleep loss would compromise the efficacy of a reduced-calorie diet on excess adiposity [117]. Overweight and obese middle-aged menand womenwere randomlyassignedto 8.5 or $5.5 \mathrm{~h}$ sleep opportunity during 14 nights in conjunction with moderate caloric restriction. At the end of the 2 weeks of sleep curtailment, the proportion of weight lost as fat was decreased by $55 \%$, and the loss of fat-free body mass was increased by $60 \%$. These results indicate that lack of sleep may attenuate the efficacy of dietary interventions for fat loss [117].

Twelve studies assessed the impact of partial sleep deprivation on leptin and ghrelin [11, 62, $99,116,117,122,144,146,154,161,162,194]$. Three studies assessed leptin at more than 2 time points in a rested sleep condition and in a sleep restriction condition in normal-weight men after similar food intake had been enforced in both conditions. All found decreased levels of anorexigenic leptin after sleep loss [62, 161, 162]. The four studies that provided ad libitum food access prior to or during leptin assessments found unchanged or increased leptin levels after sleep restriction [11,116, 146, 154]. As leptin levels are enhanced by food intake and correlate with the degree of obesity [25], these latter results may be the expected consequence of the positive energy balance achieved by increased food intake [11, 116, 146] and weight gain $[11,116]$. Similarly, these studies did not observe changes in ghrelin levels. The remaining five studies observed unchanged or increased, rather than decreased, leptin levels after sleep restriction although food intake was similar in both sleep conditions. Methodological differences may contribute to this discrepancy. For example, in the study 
that submitted the subjects to caloric restriction, leptin levels declined in parallel with the loss of weight and adiposity without a significant independent effect of sleep loss: The negative energy balance most likely overrode the impact of sleep duration [117]. However, increased ghrelin levels and elevated hunger scores were observed in the sleep restriction condition, suggesting that, in contrast to what was observed with leptin, sleep loss was able to exacerbate the upregulation of ghrelin and hunger triggered by a negative energy balance. In the studies by Leeuwen et al., a single assessment of leptin was performed at 0730 hours after five nights of $4 \mathrm{~h}$ in bed (bedtimes from 0300 to 0700 hours) and after five nights of habitual sleep (bedtimes from 2300 to 0700 hours) [194]. As the nocturnal elevation in leptin levels is influenced both by sleep and circadian rhythmicity [36], the elevation of leptin levels may have occurred later due to the shifted short bedtimes, resulting in higher morning leptin levels. In the study by Omisade et al. [122], bedtimes were restricted to $3 \mathrm{~h}$ for only 1 day, and leptin levels were measured only at 2 time points during daytime. In the study by Schmid et al. [144] that obtained a single blood draw after one single night of $4.5 \mathrm{~h}$ in bed, leptin was unaffected, whereas hunger and ghrelin were increased. The results of these two latter studies may be compared to results from a population-based study that assessed habitual sleep by diaries and obtained a morning single blood draw after a polysomnographically (PSG) recorded night [174]. The authors found increased ghrelin that correlated mainly with acute sleep loss as measured by PSG immediately prior to blood sampling, while reduced leptin correlated with chronic sleep restriction indicated by selfreported sleep measures. Thus, one single night of sleep deprivation may not be sufficient to elicit changes in leptin. These findings are in agreement with the role of leptin in signaling long-term nutritional status, while ghrelin is more involved in acute hunger [174]. Finally, the fifth study did not observe changes in leptin and ghrelin levels after two nights of $5 \mathrm{~h}$ in bed vs. after a fully rested night ( $8-10 \mathrm{~h}$ in bed), but sleep restriction resulted in reduced satiety and lower levels of PYY, an anorexigenic peptide produced by the gastrointestinal tract in response to food intake [99]. Although sleep was not monitored and hormonal levels were assessed at a single time point upon awakening, it is the first report of decreased PYY levels after sleep restriction in humans, which could represent another mechanism underlying the reduced feeling of satiety consistently reported by sleep-deprived individuals.

Inconsistent results regarding leptin and ghrelin may also be partly attributed to differences in sample sizes, severity of sleep restriction, and study populations (Table 2). More specifically, differences in body composition and prevalence of obstructive sleep apnea (OSA) may be particularly relevant, as they both alter leptin and ghrelin regulation as well as leptin action. Obesity is associated with hypoghrelinemia, hyperleptinemia, and leptin resistance, while OSA is associated with hyperghrelinemia, hyperleptinemia, and leptin resistance. It is therefore inappropriate to assume that the impact of sleep duration on leptin and ghrelin observed in normal weight individuals will generalize to obese subjects, especially if they also suffer from OSA. In favor of this hypothesis, Table 2 shows that sleep loss resulted in increased leptin and no change in ghrelin in studies that enrolled subjects with a higher BMI than studies that reported decreased leptin and increased ghrelin (average upper range of BMI of 40.3 and 32.8, respectively vs. 26.5 and 27.6, respectively). These results suggest that short sleep may worsen the hyperleptinemia and leptin resistance typically associated with excess weight in obese subjects. A few observational, epidemiologic studies that have examined the cross-sectional association between sleep duration, leptin, and ghrelin have also yielded contradictory results. In accordance with most experimental studies conducted in normal weight individuals, the Wisconsin Sleep Cohort Study and the Québec Family Study have shown reduced leptin levels, after controlling for BMI or adiposity, in habitual short sleepers [22, 174]. Higher ghrelin levels were also found to be associated with short sleep [174]. In contrast to these two studies that enrolled men and women of various body composition (lean, overweight, and obese), three subsequent studies did not confirm the link between sleep duration, leptin and ghrelin levels: One involved only 
overweight postmenopausal women [94], another one only women mostly overweight or obese with type 2 diabetes [209], and the last one only obese subjects [83]. Finally, a recent report of the Cleveland Family Study found associations between sleep duration and leptin that were in the opposite expected direction: Each hour reduction in total sleep time assessed by PSG during $7 \mathrm{~h} 45$ of enforced time in bed was associated with a $6 \%$ increase in morning leptin after adjustment for various confounders, including adiposity and sleep apnea severity. Since this cohort was designed to study the genetic basis of sleep apnea, the prevalence of OSA and obesity was very high. Although these observational studies adjusted for BMI or adiposity and sometimes for indexes of OSA severity in their analyses, they did not assess the association between sleep and leptin for various body compositions and sleep apnea status (e.g., lean, overweight, or obese, with or without OSA). Studies are warranted to determine whether the discrepant leptin and ghrelin results between studies, both experimental and observational, are due to methodological differences or if they represent physiological differences between lean, overweight, and obese individuals with or without OSA.

Sleep duration seems to modulate the neuroendocrine regulation of appetite in a dosedependent manner. In a study that assessed the 24-h leptin profiles after 6 days of 4-, 8-, and 12-h bedtimes in healthy lean young men under conditions of stable caloric intake and activity levels, all characteristics of the 24-h leptin profile (overall mean, nocturnal maximum, and amplitude) gradually increased from the 4 - to the 12-h bedtime condition [161]. A dose-response relationship between amounts of sleep, hunger ratings, and ghrelin levels was also reported in a study involving TSD, 4.5- and 7-hbedtimes [144]. These results are in accordance with a meta-analysis of epidemiologic studies that reported a trend for a dose-response relationship between reduced sleep duration and increased risk of obesity [23].

Sleep duration and energy expenditure-Energy homeostasis is reached when energy intake meets EE. Beside changes in the regulation of food intake, reduced EE during sleep loss could represent another mechanism contributing to the link between short sleep and increased weight.

Although it is well established that EE is lower during sleep [10, 53, 78, 207], relatively few studies have evaluated the impact of sleep loss on daytime and/or $24 \mathrm{~h} \mathrm{EE}$. In comparison to a regular sleep-wake cycle, resting and postprandial EE assessed in the morning following a night of TSD were found to be 5\% and 20\% lower, respectively [5]. Twenty-four hour EE assessed in a whole-room indirect calorimeter during $16 \mathrm{~h}$ of wakefulness followed by a night of TSD was increased by 7\% ( 134 kcals), in comparison to anormal sleep-wake cycle with $8 \mathrm{~h}$ bedtimes. Interestingly, this study also reported that the $24 \mathrm{~h}$ EE measured over the day and $8 \mathrm{~h}$ recovery sleep following the night of TSD decreased by 5\% ( $96 \mathrm{kcal})$ in comparison to baseline [78]. These results suggest that compensatory mechanisms are taking place after sleep deprivation in order to limit the energetic cost of extended wake. Thus, it may be possible that recurrent sleep restriction does not significantly affect $24 \mathrm{~h} \mathrm{EE}$. In accordance with this hypothesis, Bosy-Westphal et al. [11] found no change in resting EE measured by indirect calorimetry in 14 healthy women studied after four nights of $\sim 5.5 \mathrm{~h}$ in bed compared to $\sim 9 \mathrm{~h}$ sleep for two nights, even when adjusted for fat-free mass or total EE. Similarly, in a protocol involving 14 nights of $5.5 \mathrm{~h}$ vs. 14 nights of $8.5 \mathrm{~h}$ in bed in healthy overweight subjects, total EE assessed by the gold standard doubly labeled water method, resting metabolic rate assessed by indirect calorimetry, and the thermic effect of food were similar in both bedtime conditions [115]. Finally, resting metabolic rate and total EE measured with the doubly labeled water method over 5 days of $4 \mathrm{~h}$ bedtimes and over 5 days of $9 \mathrm{~h}$ bedtimes in middle-aged men and women were similar in both bedtime conditions. Thus, the $20 \%$ increase in self-reported food consumption in the study of Bosy-Westphal et 
al., the increased consumption of snacks in the study of Nedeltcheva et al., and the $\sim 300$ $\mathrm{kcal} / \mathrm{day}$ increase in energy intake in the study of St-Onge et al. were not related to a comparable rise in energy needs and would, if sustained, eventually result in weight gain $[11,115,170]$.

To note, the study of Nedeltcheva et al. was conducted under controlled sedentary conditions, and the results obtained for EE may have been different if the subject had been allowed physical activity. Indeed, sleep problems and/or excessive daytime sleepiness significantly reduce physical activity [13, 203]. The four studies that examined the impact of behavioral sleep restriction on physical activity have yielded contradictory results; the possible involvement of reduced activity-related EE in the link between short sleep and increased obesity risk remains to be determined. In comparison with a rested condition, physical activity was found to be decreased after two nights of $4 \mathrm{~h}$ sleep [146], increased after one night of $4 \mathrm{~h}$ sleep [14], and unaffected after two nights of $6 \mathrm{~h}$ and 1 night of $4 \mathrm{~h}$ in

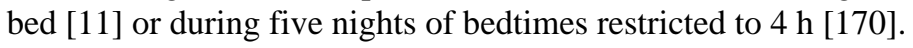

Thus, from evidence obtained so far, it appears that short sleep affects energy balance because of an upregulation of orexigenic hormones and a downregulation of anorexigenic hormones associated with increased hunger and caloric intake, rather than because of a reduced EE.

\section{Obstructive sleep apnea and type 2 diabetes}

OSA is a highly prevalent chronic sleep disorder characterized by repetitive episodes of upper airway obstruction leading to intermittent hypoxemia and/or hypercapnia and sleep fragmentation (see review of Leung et al. in the same issue). OSA is diagnosed by polysomnography and defined as an apnea-hypopnea index (AHI; the number of apneas and hypopneas per hour of sleep) $>5$. In the general population, the prevalence of OSA is around $17 \%$ [215]. Obesity is a major risk factor for OSA, and recent estimates suggest that excess weight is responsible for $41-58 \%$ of OSA [215]. The prevalence of OSA in the morbidly obese population is reaching a striking high 50-98\% [141]. It is now well-documented that OSA, independently of age, sex, BMI, and other confounders, is associated with glucose intolerance, insulin resistance, and diabetes (for review, see [175, 177]). In patients with type 2 diabetes, the prevalence of OSA assessed with full night polysomnography, i.e., the gold standard method for the diagnosis of OSA, ranged from 58\% to $86 \%$ [2, 45, 52, 134]. The highest estimate was obtained when only obese type 2 diabetics were considered [52]. This emerging evidence for an exceptionally high rate of OSA in type 2 diabetes has important implications for clinical practice; OSA should be systematically evaluated and treated in diabetic patients, especially if they are obese. While OSA involves respiratory disturbances and hypoxic stress, reduced sleep quality due to sleep fragmentation and low levels of SWS as well as reduced total sleep time are major components of this condition. The alterations of glucose regulation observed with experimentally induced reduced sleep duration and quality suggest that poor and short sleep, in addition to hypoxia, could be significant contributors to altered glucose homeostasis and weight gain in OSA.

The first-line therapy for OSA is continuous positive airway pressure (CPAP), and a number of studies have examined the impact of this treatment on cardiovascular risk factors. Regarding glucose homeostasis, 21 studies have involved mostly or exclusively non-diabetic patients, while seven have focused on patients with type 2 diabetes. Another seven did not have specific exclusion criteria regarding glucose tolerance status. The results are presented in Table 3.

The most investigated parameter of glucose homeostasis in OSA patients is SI, which was assessed in 30 studies. In 12 of these, an improvement in SI was reported after as little as 2 
days of CPAP treatment in non-obese patients [65]and 1 week in obese patients [88]. However, very few of these reports were randomized controlled studies. In the study by Lam et al., 31 patients underwent CPAP treatment, and 30 patients were randomized to sham CPAP; the two patient groups were comparable in terms of age, BMI, AHI, and daytime sleepiness. SI was evaluated by short insulin tolerance test 1 and 12 weeks after the start of the CPAP treatment. The patients randomized to sham CPAP showed unchanged SI at both evaluations, while a significant improvement in SI, but no other marker of glucose homeostasis, was obtained in those who received adequate treatment. Another group [36] included data about both obese non-OSA controls and non-compliant OSA patients $(<4 \mathrm{~h}$ CPAP use per night), and observed improvement in SI, assessed by the homeostatic model assessment (HOMA-IR), only in the patients with good treatment adherence. In this case, the groups were comparable for age and AHI (except for the non-OSA controls), but BMI was slightly higher in the treated OSA patients. One study reporting unchanged SI in type 2 diabetes patients after therapeutic CPAP also included a group of patients who underwent sham CPAP [206]; in this study, the patients underwent a hyperinsulinemic-euglycemic clamp, the gold standard for evaluation of SI, but the average nightly therapeutic CPAP use was only $3.3 \pm 2.6 \mathrm{~h}$. Although both objective and subjective measures of daytime sleepiness were significantly improved, the change in AHI with CPAP was not reported. Another study with negative results was a randomized placebo-controlled blinded cross-over trial, comparing 6 weeks of therapeutic CPAP vs. sham CPAP in obese OSA patients [30].

In seven reports, the improved SI resulted in an amelioration of glucose tolerance $[4,24,68$, $71,118,169,205]$. Two studies involving patients with type 2 diabetes $[4,68]$ reported, after 3-4 months of CPAP, a decrease in HbA1c similar to that induced by metformin and thiazolinediones [214]. Furthermore, two studies reported lower fasting glucose and insulin levels in CPAP treated patients [42, 71], while one observed improved fasting glucose concentrations but unchanged fasting insulin levels [142].

Out of four studies that evaluated beta-cell function [31, 71, 109, 180], only one [31] observed an improvement in this parameter, as assessed by the homeostatic model assessment (HOMA-beta); somewhat surprisingly, all other markers of glucose homeostasis (fasting glucose and insulin levels, HOMA-IR) were unchanged by 2 months of CPAP treatment. The compliance to CPAP was not reported.

Finally, a population-based study involving 28 OSA patients and 28 controls matched for age, smoking status, and comorbidities found a significant decrease only in fasting insulin levels, after 3 weeks of CPAP treatment, while the decrease in SI, assessed by HOMA-IR, failed to reach statistical significance [93]. It is possible that a longer treatment period would have brought significant changes in HOMA-IR as well.

One group [110] focused on children with metabolic syndrome and sleep-disordered breathing treated with CPAP for 12 months and observed no improvement in glucose tolerance or SI; however, the compliance to CPAP is not reported.

To summarize, 17 of the 35 studies reported an improvement in at least one parameter of glucose homeostasis following CPAP treatment in OSA patients, both diabetics and nondiabetics. The parameter most consistently found to be positively impacted by CPAP is SI, which is interesting since OSA has been found to be independently associated with insulin resistance $[77,131]$. However, there were only five controlled studies among those published in literature, of which three yielded positive results, while the other two were unable to demonstrate a beneficial impact of CPAP on glucose homeostasis.

Most of the positive studies focused either on only non diabetic patients $(n=10)$ or only diabetic patients $(n=5)$, while almost half of the studies with negative results enrolled 
patients regardless of their glucose tolerance status (only non-diabetics $n=7$, only impaired glucose tolerance $n=1$, only diabetics $n=1$ ). Average duration of treatment was comparable in the studies with positive and negative results (5.3 \pm 5.8 vs $4.8 \pm 6.2$ months). However, the compliance to CPAP, for the articles that report it, was on average higher in the studies with positive findings than in the negative studies $(5.4 \pm 0.5 \mathrm{vs} 4.8 \pm 0.8 \mathrm{~h} / \mathrm{night})$. Methodological differences may also account for the variability of results obtained: four positive studies relied on the hyperinsulinemic-euglycemic clamp technique to assess SI [15, 65, 66, 142], which is considered the gold standard to evaluate SI; another two used continuous glucose monitoring (CGMS) [4, 205], which provides 288 readings of interstitial glucose levels per $24 \mathrm{~h}$ (every $5 \mathrm{~min}$ ) and allows a very accurate evaluation of glucose homeostasis [60]; and one used the minimal model estimate of SI derived from the analysis of ivGTT [180], which has a coefficient of variation for SI similar of that of the glucose clamp and allows to evaluate SI, glucose tolerance, and beta cell function in one single test [108]. Conversely, most of the negative studies assessed glucose metabolism with parameters derived from the results of a single fasting blood sample. HOMA-IR has been found to correlate reasonably well with the glucose clamp and minimal model estimates of insulin sensitivity/resistance in several studies of distinct populations. However, it is a measure of basal insulin sensitivity/ resistance and does not provide information about dynamic conditions [201]. Furthermore, it was suggested that the logarithmic transformation of HOMA-IR may be a more appropriate measure for the evaluation of insulin resistance in individuals with glucose intolerance and insulin-resistant conditions [108].

Nevertheless, more controlled studies are necessary to accurately evaluate the impact of CPAP on the alterations of glucose homeostasis observed in OSA patients. The mechanisms through which CPAP may improve glucose metabolism include better sleep quality and continuity and correction of the intermittent hypoxia leading to increased SWS [47, 51, 61, $69,180]$, decreased activity of the sympathetic nervous system [111, 157], and decreased weight and/or adiposity through improvement of hormones involved in appetite regulation [165]. The effect of CPAP on the activity of the hypothalamic-pituitary-adrenal axis is still debated [184]. However, two studies involving frequent (q30 and q10 min) blood sampling over a 24-h period observed a decrease in cortisol and ACTH levels in OSA patients following treatment $[72,197]$.

\section{Conclusion}

Over the past 10-15 years, growing evidence from both epidemiological and experimental studies has accumulated to show that metabolic function is tightly linked to sleep duration and sleep quality. The experimental studies, in particular, are providing greater insight into the mechanisms underlying the relationship between sleep, glucose homeostasis, and weight regulation, which involve peripheral insulin sensitivity, insulin secretion by the pancreatic beta cells, and brain glucose utilization, as well as several hormones influencing appetite/ satiety and energy homeostasis. There is an obvious necessity to increase public awareness about the contribution of the self-imposed sleep curtailment to the pandemic of obesity and diabetes. Furthermore, OSA, a condition highly prevalent not only in obesity but also in diabetes and other metabolic disorders, needs to be more widely diagnosed. The evidence of a beneficial impact of CPAP treatment on glycemic control in patients with OSA is not as clear cut as for other cardiovascular risk factors, but definitely warrants further investigation.

\section{Acknowledgments}

Some of the research described in this article was supported by US National Institute of Health grants P01 AG-11412, R01 HL-075079, P60 DK-20595, R01 DK-0716960, R01 HL-075025, and M01 RR000055, by US 
Department of Defense award W81XWH-07-2-0071, by Belgian "Fonds de la Recherche Scientifique Médicale" (FRSM-3.4583.02), "Fonds National de la Recherche Scientifique" (FNRS) and "CARE Foundation" grants, by INSERM U628, and by Claude Bernard University of Lyon, France.

\section{References}

1. Ahima RS, Saper CB, Flier JS, Elmquist JK. Leptin regulation of neuroendocrine systems. Front Neuroendocrinol. 2000; 21:263-307. [PubMed: 10882542]

2. Aronsohn RS, Whitmore H, Van Cauter E, Tasali E. Impact of untreated obstructive sleep apnea on glucose control in type 2 diabetes. Am J Respir Crit Care Med. 2010; 181:507-513. [PubMed: 20019340]

3. Avram AM, Jaffe CA, Symons KV, Barkan AL. Endogenous circulating ghrelin does not mediate growth hormone rhythmicity or response to fasting. J Clin Endocrinol Metabol. 2005; 90:29822987.

4. Babu AR, Herdegen J, Fogelfeld L, Shott S, Mazzone T. Type 2 diabetes, glycemic control, and continuouspositive airway pressure in obstructive sleep apnea. Arch Intern Med. 2005; 165:447452. [PubMed: 15738376]

5. Benedict C, et al. Acute sleep deprivation reduces energy expenditure in healthy men. Am J Clin Nutr. 2011; 93:1229-1236. [PubMed: 21471283]

6. Bergman RN. Lilly lecture 1989. Toward physiological understanding of glucose tolerance. Minimal-model approach. Diabetes. 1989; 38:1512-1527. [PubMed: 2684710]

7. Bergman RN. Minimal model: perspective from 2005. Horm Res. 2005; 64(Suppl 3):8-15. [PubMed: 16439839]

8. Bo S, et al. Contributors to the obesity and hyperglycemia epidemics. A prospective study in a population-based cohort. Int J Obes. 2011 doi:10.1038/ijo.2011.5.

9. Bodosi B, et al. Rhythms of ghrelin, leptin, and sleep in rats: effects of the normal diurnal cycle, restricted feeding, and sleep deprivation. Am J Physiol. 2004; 287:R1071-R1079.

10. Bonnet MH, Berry RB, Arand DL. Metabolism during normal, fragmented, and recovery sleep. J Appl Physiol. 1991; 71:1112-1118. [PubMed: 1757306]

11. Bosy-Westphal A, et al. Influence of partial sleep deprivation on energy balance and insulin sensitivity in healthy women. Obes Facts. 2008; 1:266-273. [PubMed: 20054188]

12. Boyle PJ, et al. Diminished brain glucose metabolism is a significant determinant for falling rates of systemic glucose utilization during sleep in normal humans. J Clin Invest. 1994; 93:529-535. [PubMed: 8113391]

13. Briones B, et al. Relationship between sleepiness and general health status. Sleep. 1996; 19:583588. [PubMed: 8899938]

14. Brondel L, Romer MA, Nougues PM, Touyarou P, Davenne D. Acute partial sleep deprivation increases food intake in healthy men. Am J Clin Nutr. 2010; 91:1550-1559. [PubMed: 20357041]

15. Brooks B, et al. Obstructive sleep apnea in obese noninsulin-dependent diabetic patients: effects of continuous positive airway pressure treatment on insulin responsiveness. J Clin Endocrinol Metabol. 1994; 79:1681-1685.

16. Buxton OM, et al. Sleep restriction for 1 week reduces insulin sensitivity in healthy men. Diabetes. 2010; 59:2126-2133. [PubMed: 20585000]

17. Callahan HS, et al. Postprandial suppression of plasma ghrelin level is proportional to ingested caloric load but does not predict intermeal interval in humans. J Clin Endocrinol Metabol. 2004; 89:1319-1324.

18. Cappuccio FP, et al. Meta-analysis of short sleep duration and obesity in children and adults. Sleep. 2008; 31:619-626. [PubMed: 18517032]

19. Cappuccio FP, D'Elia L, Strazzullo P, Miller MA. Quantity and quality of sleep and incidence of type 2 diabetes: a systematic review and meta-analysis. Diabetes Care. 2010; 33:414-420. [PubMed: 19910503]

20. Carneiro G, et al. Continuous positive airway pressure therapy improves hypoadiponectinemia in severe obese men with obstructive sleep apnea without changes in insulin resistance. Metab Syndr Relat Disord. 2009; 7:537-542. [PubMed: 19558268] 
21. Carter PJ, Taylor BJ, Williams SM, Taylor RW. Longitudinal analysis of sleep in relation to BMI and body fat in children: the FLAME study. BMJ. 2011; 342:d2712. [PubMed: 21622518]

22. Chaput JP, Despres JP, Bouchard C, Tremblay A. Short sleep duration is associated with reduced leptin levels and increased adiposity: results from the Quebec family study. Obesity (Silver Spring, Md). 2007; 15:253-261.

23. Chen X, Beydoun MA, Wang Y. Is sleep duration associated with childhood obesity? A systematic review and meta-analysis. Obesity (Silver Spring, Md). 2008; 16:265-274.

24. Chin K, et al. Changes in intra-abdominal visceral fat and serum leptin levels in patients with obstructive sleep apnea syndrome following nasal continuous positive airway pressure therapy. Circulation. 1999; 100:706-712. [PubMed: 10449691]

25. Chin-Chance C, Polonsky KS, Schoeller DA. Twenty-four-hour leptin levels respond to cumulative short-term energy imbalance and predict subsequent intake. J Clin Endocrinol Metabol. 2000; 85:2685-2691.

26. Chung S, Yoon IY, Lee CH, Kim JW. The effects of nasal continuous positive airway pressure on vascular functions and serum cardiovascular risk factors in obstructive sleep apnea syndrome. Sleep Breath. 2011; 15:71-76. [PubMed: 20084550]

27. Cizza G, et al. Treatment of obesity with extension of sleep duration: a randomized, prospective, controlled trial. Clin Trials. 2010; 7:274-285. [PubMed: 20423926]

28. Colditz GA, Willett WC, Rotnitzky A, Manson JE. Weight gain as a risk factor for clinical diabetes mellitus in women. Ann Intern Med. 1995; 122:481-486. [PubMed: 7872581]

29. Comondore VR, et al. The impact of CPAP on cardiovascular biomarkers in minimally symptomatic patients with obstructive sleep apnea: a pilot feasibility randomized crossover trial. Lung. 2009; 187:17-22. [PubMed: 18795367]

30. Coughlin SR, Mawdsley L, Mugarza JA, Wilding JP, Calverley PM. Cardiovascular and metabolic effects of CPAP in obese males with OSA. Eur Respir J. 2007; 29:720-727. [PubMed: 17251237]

31. Cuhadaroglu C, Utkusavas A, Ozturk L, Salman S, Ece T. Effects of nasal CPAP treatment on insulin resistance, lipid profile, and plasma leptin in sleep apnea. Lung. 2009; 187:75-81. [PubMed: 19127383]

32. Cummings DE, et al. A preprandial rise in plasma ghrelin levels suggests a role in meal initiation in humans. Diabetes. 2001; 50:1714-1719. [PubMed: 11473029]

33. Cummings DE, Frayo RS, Marmonier C, Aubert R, Chapelot D. Plasma ghrelin levels and hunger scores in humans initiating meals voluntarily without time- and food-related cues. Am J Physiol Endocrinol Metab. 2004; 287:E297-E304. [PubMed: 15039149]

34. Danaei G, et al. National, regional, and global trends in fasting plasma glucose and diabetes prevalence since 1980: systematic analysis of health examination surveys and epidemiological studies with 370 country-years and 2.7 million participants. Lancet. 2011; 378:31-40. [PubMed: 21705069]

35. Danguir J, Nicolaidis S. Dependence of sleep on nutrients' availability. Physiol Behav. 1979; 22:735-740. [PubMed: 225752]

36. de Lima AMJ, et al. Effects of nasal continuous positive airway pressure treatment on oxidative stress and adiponectin levels in obese patients with obstructive sleep apnea. Respiration. 2010; 79:370-376. [PubMed: 19590157]

37. DeFronzo RA. Pathogenesis of type 2 diabetes mellitus. Med Clin North Am. 2004; 88:787-835. ix. [PubMed: 15308380]

38. Diethelm K, Bolzenius K, Cheng G, Remer T, Buyken AE. Longitudinal associations between reported sleep duration in early childhood and the development of body mass index, fat mass index and fat free mass index until age 7. Int J Pediatr Obes. 2011; 6:e114-e123. [PubMed: 21604964]

39. Dimaraki EV, Jaffe CA. Role of endogenous ghrelin in growth hormone secretion, appetite regulation and metabolism. Rev Endocr Metab Disord. 2006; 7:237-249. [PubMed: 17195943]

40. Dinges, DF.; Chugh, DK. Physiological correlates of sleep deprivation. In: Kinney, JM.; Tucker, HN., editors. Physiology, stress, and malnutrition: functional correlates, nutritional intervention. Lippincott-Raven; Philadelphia: 1997.

41. Donga E, et al. A single night of partial sleep deprivation induces insulin resistance in multiple metabolic pathways in healthy subjects. J Clin Endocrinol Metabol. 2010; 95:2963-2968. 
42. Dorkova Z, Petrasova D, Molcanyiova A, Popovnakova M, Tkacova R. Effects of continuous positive airway pressure on cardiovascular risk profile in patients with severe obstructive sleep apnea and metabolic syndrome. Chest. 2008; 134:686. [PubMed: 18625666]

43. Dworak M, McCarley RW, Kim T, Kalinchuk AV, Basheer R. Sleep and brain energy levels: ATP changes during sleep. J Neurosci. 2010; 30:9007-9016. [PubMed: 20592221]

44. Dzaja A, et al. Sleep enhances nocturnal plasma ghrelin levels in healthy subjects. Am J Physiol Endocrinol Metab. 2004; 286:E963-E967. [PubMed: 14871884]

45. Einhorn D, et al. Prevalence of sleep apnea in a population of adults with type 2 diabetes mellitus. Endocr Pract. 2007; 13:355-362. [PubMed: 17669711]

46. Eliassen AH, Colditz GA, Rosner B, Willett WC, Hankinson SE. Adult weight change and risk of postmenopausal breast cancer. JAMA. 2006; 296:193-201. [PubMed: 16835425]

47. Eskelinen V, Uibu T, Himanen SL. nCPAP treatment of obstructive sleep apnea increases slow wave sleep in prefrontal EEG. Clin EEG Neurosci. 2007; 38:148. [PubMed: 17844944]

48. Espelund U, et al. Fasting unmasks a strong inverse association between ghrelin and cortisol in serum: studies in obese and normal-weight subjects. J Clin Endocrinol Metabol. 2005; 90:741746.

49. Estabrooke IV, et al. Fos expression in orexin neurons varies with behavioral state. J Neurosci. 2001; 21:1656-1662. [PubMed: 11222656]

50. Feng DD, et al. Ghrelin and obestatin modulate growth hormone-releasing hormone release and synaptic inputs onto growth hormone-releasing hormone neurons. Eur J Neurosci. 2011; 34:732744. [PubMed: 21777303]

51. Fietze I, Bravo S Quispe, Hänsch T, Röttig J, Baumann C. Arousals and sleep stages in patients with obstructive sleep apnoea syndrome: changes under nCPAP treatment. J Sleep Res. 1997; 6:128-133. [PubMed: 9377532]

52. Foster GD, et al. Obstructive sleep apnea among obese patients with type 2 diabetes. Diabetes Care. 2009; 32:1017-1019. [PubMed: 19279303]

53. Fraser G, Trinder J, Colrain IM, Montgomery I. Effect of sleep and circadian cycle on sleep period energy expenditure. J Appl Physiol. 1989; 66:830-836. [PubMed: 2708211]

54. Garcia G, et al. Glucose metabolism in older adults: a study including subjects more than 80 years of age. J Am Geriatr Soc. 1997; 45:813-817. [PubMed: 9215331]

55. Garcia JM, Sharafkaneh H, Hirshkowitz M, Elkhatib R, Sharafkhaneh H. Weight and metabolic effects of CPAP in obstructive sleep apnea patients with obesity. Respir Res. 2011; 12:80-88. [PubMed: 21676224]

56. Gasco V, et al. Endocrine and metabolic actions of ghrelin. Endocr Dev. 2010; 17:86-95. [PubMed: 19955759]

57. Gonzalez-Ortiz M, Martinez-Abundis E, Balcazar-Munoz BR, Pascoe-Gonzalez S. Effect of sleep deprivation on insulin sensitivity and cortisol concentration in healthy subjects. Diabetes Nutr Metab. 2000; 13:80-83. [PubMed: 10898125]

58. Granata R, Baragli A, Settanni F, Scarlatti F, Ghigo E. Unraveling the role of the ghrelin gene peptides in the endocrine pancreas. J Mol Endocrinol. 2010; 45:107-118. [PubMed: 20595321]

59. Gronfier C, Brandenberger G. Ultradian rhythms in pituitary and adrenal hormones: their relations to sleep. Sleep Med Rev. 1998; 2:17-29. [PubMed: 15310510]

60. Gross TM, Mastrototaro JJ. Efficacy and reliability of the continuous glucose monitoring system. Diabetes Technol Ther. 2000; 2:19-26.

61. Guilleminault $\mathrm{C}$, et al. Sleep and daytime sleepiness in upper airway resistance syndrome compared to obstructive sleep apnoea syndrome. Eur Respir J. 2001; 17:838. [PubMed: 11488314]

62. Guilleminault C, et al. Preliminary observations on the effects of sleep time in a sleep restriction paradigm. Sleep Med. 2003; 4:177-184. [PubMed: 14592319]

63. Gupta NK, Mueller WH, Chan W, Meininger JC. Is obesity associated with poor sleep quality in adolescents? Am J Hum Biol. 2002; 14:762-768. [PubMed: 12400037]

64. Haddad GG. Does the brain gain back energy during sleep? But what does it mean? Sleep. 2011; 34:835-836. author reply 841-833. [PubMed: 21731130] 
65. Harsch IA, et al. Continuous positive airway pressure treatment rapidly improves insulin sensitivity in patients with obstructive sleep apnea syndrome. Am J Respir Crit Care Med. 2004; 169:156162. [PubMed: 14512265]

66. Harsch IA, et al. The effect of continuous positive airway pressure treatment on insulin sensitivity in patients with obstructive sleep apnoea syndrome and type 2 diabetes. Respiration. 2004; 71:252-259. [PubMed: 15133345]

67. Hasler G, et al. The association between short sleep duration and obesity in young adults: a 13-year prospective study. Sleep. 2004; 27:661-666. [PubMed: 15283000]

68. Hassaballa HA, Tulaimat A, Herdegen JJ, Mokhlesi B. The effect of continuous positive airway pressure on glucose control in diabetic patients with severe obstructive sleep apnea. Sleep \& breathing = Schlaf \& Atmung. 2005; 9:176-180.

69. Heinzer R, et al. Slow-wave activity in sleep apnea patients before and after continuous positive airway pressure treatment*. Chest. 2001; 119:1807. [PubMed: 11399708]

70. Heller HC. Repeatability is not the same as accuracy. Sleep. 2011; 34:839. author reply 841-833. [PubMed: 21731132]

71. Henley DE, et al. Plasma apelin levels in obstructive sleep apnea and the effect of continuous positive airway pressure therapy. J Endocrinol. 2009; 203:181-188. [PubMed: 19643928]

72. Henley DE, et al. Hypothalamic-pituitary-adrenal axis activation in obstructive sleep apnea: the effect of continuous positive airway pressure therapy. J Clin Endocrinol Metabol. 2009; 94:4234.

73. Hill JO, Wyatt HR, Reed GW, Peters JC. Obesity and the environment: where do we go from here? Science (New York, NY). 2003; 299:853-855.

74. Horne J. Obesity and short sleep: unlikely bedfellows? Obes Rev. 2011; 12:e84-e94. [PubMed: 21366837]

75. Institut National de Prévention et d'Education pour la Santé. Les français et leur sommeil. http://www.inpes.sante.fr/70000/dp/08/dp080310.pdf.1-45

76. Ip MS, Lam KS, Ho C, Tsang KW, Lam W. Serum leptin and vascular risk factors in obstructive sleep apnea. Chest. 2000; 118:580-586. [PubMed: 10988175]

77. Ip MSM, et al. Obstructive sleep apnea is independently associated with insulin resistance. Am J Respir Crit Care Med. 2002; 165:670. [PubMed: 11874812]

78. Jung CM, et al. Energy expenditure during sleep, sleep deprivation and sleep following sleep deprivation in adult humans. J Physiol. 2011; 589:235-244. [PubMed: 21059762]

79. Kahn SE. The relative contributions of insulin resistance and beta-cell dysfunction to the pathophysiology of type 2 diabetes. Diabetologia. 2003; 46:3-19. [PubMed: 12637977]

80. Knutson KL. Sleep duration and cardiometabolic risk: a review of the epidemiologic evidence. Best Pract Res Clin Endocrinol Metab. 2010; 24:731-743. [PubMed: 21112022]

81. Knutson KL, Leproult R. Apples to oranges: comparing long sleep to short sleep. J Sleep Res. 2010; 19:118. [PubMed: 20470264]

82. Knutson KL, Van Cauter E. Associations between sleep loss and increased risk of obesity and diabetes. Ann N Y Acad Sci. 2008; 1129:287-304. [PubMed: 18591489]

83. Knutson KL, Galli G, Zhao X, Mattingly M, Cizza G. No association between leptin levels and sleep duration or quality in obese adults. Obesity (Silver Spring). 2011 doi:10.1038/oby.2011.248.

84. Kolaczynski JW, et al. Responses of leptin to short-term fasting and refeeding in humans: a link with ketogenesis but not ketones themselves. Diabetes. 1996; 45:1511-1515. [PubMed: 8866554]

85. Koutkia P, Canavan B, Breu J, Johnson ML, Grinspoon SK. Nocturnal ghrelin pulsatility and response to growth hormone secretagogues in healthy men. Am J Physiol Endocrinol Metab. 2004; 287:E506-E512. [PubMed: 15138154]

86. Kuhn E, Brodan V, Brodanova M, Rysanek K. Metabolic reflection of sleep deprivation. Act Nerv Super (Praha). 1969; 11:165-174. [PubMed: 5798779]

87. Kumor M, Bielicki P, Pzybylowski T, Rubinsztajn R, Zielinski J. Three-month continuous positive airway pressure (CPAP) treatmetn decreases total LDL-cholesterol levels but does not affect serum homocysteine and leptin levels in patients with obstructive sleep apnea syndrome (OSAS) without co-existent ischaemic heart disease (IHD). Pol Pneumonol Allergol. 2011; 79:173-183. 
88. Lam JC, et al. A randomised controlled trial of nasal continuous positive airway pressure on insulin sensitivity in obstructive sleep apnoea. Eur Respir J. 2010; 35:138-145. [PubMed: 19608589]

89. Landhuis CE, Poulton R, Welch D, Hancox RJ. Childhood sleep time and long-term risk for obesity: a 32-year prospective birth cohort study. Pediatrics. 2008; 122:955-960. [PubMed: 18977973]

90. Laposky AD, et al. Altered sleep regulation in leptin-deficient mice. Am J Physiol. 2006; 290:R894-R903.

91. Leproult, R.; Van Cauter, E. Marked decreased insulin sensitivity and increased evening cortisol levels following one week of partial sleep deprivation. 12th meeting of the European NeuroEndocrine Association (ENEA); Athens, Greece. 2006.

92. Lim CT, Kola B, Korbonits M, Grossman AB. Ghrelin's role as a major regulator of appetite and its other functions in neuroendocrinology. Prog Brain Res. 2010; 182:189-205. [PubMed: 20541666]

93. Lindberg E, Berne C, Elmasry A, Hedner J, Janson C. CPAP treatment of a population-based sample - what are the benefits and the treatment compliance? Sleep Med. 2006; 7:553-560. [PubMed: 16740408]

94. Littman AJ, et al. Sleep, ghrelin, leptin and changes in body weight during a 1-year moderateintensity physical activity intervention. Int J Obes. 2007; 31:466-475.

95. Liu J, et al. Novel ghrelin assays provide evidence for independent regulation of ghrelin acylation and secretion in healthy young men. J Clin Endocrinol Metabol. 2008; 93:1980-1987.

96. Lyssenko V, et al. Predictors of and longitudinal changes in insulin sensitivity and secretion preceding onset of type 2 diabetes. Diabetes. 2005; 54:166-174. [PubMed: 15616025]

97. Lyytikainen P, Rahkonen O, Lahelma E, Lallukka T. Association of sleep duration with weight and weight gain: a prospective follow-up study. J Sleep Res. 2011; 20:298-302. [PubMed: 21199039]

98. Magee L, Hale L. Longitudinal associations between sleep duration and subsequent weight gain: a systematic review. Sleep Med Rev. 2011 doi:10.1016/j.smrv.2011.05.005.

99. Magee CA, Huang X-F, Iverson DC, Caputi P. Acute sleep restriction alters neuroendocrine hormones and appetite in healthy male adults. Sleep Biol Rhythms. 2009; 7:125-127.

100. Marshall NS, Glozier N, Grunstein RR. Is sleep duration related to obesity? A critical review of the epidemiological evidence. Sleep Med Rev. 2008; 12:289-298. [PubMed: 18485764]

101. Marshall NS, et al. Changes in sleep duration and changes in weight in obese patients: the Swedish obese subjects study. Sleep Biol Rhythms. 2010; 8:63-71.

102. McAllister EJ, et al. Ten putative contributors to the obesity epidemic. Crit Rev Food Sci Nutr. 2009; 49:868-913. [PubMed: 19960394]

103. Møller N, et al. Effects of a growth hormone pulse on total and forearm substrate fluxes in humans. Am J Physiol. 1990; 258:E86-E91. [PubMed: 2405702]

104. Morselli, L.; Balbo, M.; Van Cauter, E.; Guyon, A.; Spiegel, K. Impact of sleep restriction on the regulation of appetite in middle-aged obese subjects. 4th International World Sleep Congress; Quebec City, Québec. 2011.

105. Mozaffarian D, Hao T, Rimm EB, Willett WC, Hu FB. Changes in diet and lifestyle and longterm weight gain in women and men. N Engl J Med. 2011; 364:2392-2404. [PubMed: 21696306]

106. Muller AF, et al. Ghrelin drives GH secretion during fasting in man. Eur J Endocrinol. 2002; 146:203-207. [PubMed: 11834429]

107. Mullington JM, et al. Sleep loss reduces diurnal rhythm amplitude of leptin in healthy men. J Neuroendocrinol. 2003; 15:851-854. [PubMed: 12899679]

108. Muniyappa R, Lee S, Chen H, Quon MJ. Current approaches for assessing insulin sensitivity and resistance in vivo: advantages, limitations, and appropriate usage. Am J Physiol Endocrinol Metab. 2008; 294:E15. [PubMed: 17957034]

109. Murri M, et al. Oxidative stress and metabolic changes after continuous positive airway pressure treatment according to previous metabolic disorders in sleep apnea-hypopnea syndrome patients. Transl Res. 2009; 154:111-121. [PubMed: 19665687] 
110. Nakra N, Bhargava S, Dzuira J, Caprio S, Bazzy-Asaad A. Sleep-disordered breathing in children with metabolic syndrome: the role of leptin and sympathetic nervous system activity and the effect of continuous positive airway pressure. Pediatrics. 2008; 122:e634-e642. [PubMed: 18762497]

111. Narkiewicz K, Somers V. Sympathetic nerve activity in obstructive sleep apnoea. Acta Physiol Scand. 2003; 177:385-390. [PubMed: 12609010]

112. Nass R, et al. Evidence for acyl-ghrelin modulation of growth hormone release in the fed state. $\mathrm{J}$ Clin Endocrinol Metabol. 2008; 93:1988-1994.

113. Natalucci G, Riedl S, Gleiss A, Zidek T, Frisch H. Spontaneous 24-h ghrelin secretion pattern in fasting subjects: maintenance of a meal-related pattern. Eur J Endocrinol. 2005; 152:845-850. [PubMed: 15941923]

114. National Sleep Foundation. 'Sleep in America” Poll. 2008. http://www.sleepfoundation.org./sites/default/files/2008\%20POLL\%20SOF.PDF.1-45

115. Nedeltcheva AV, Kessler L, Imperial J, Penev PD. Exposure to recurrent sleep restriction in the setting of high caloric intake and physical inactivity results in increased insulin resistance and reduced glucose tolerance. J Clin Endocrinol Metabol. 2009; 94:3242-3250.

116. Nedeltcheva AV, et al. Sleep curtailment is accompanied by increased intake of calories from snacks. Am J Clin Nutr. 2009; 89:126-133. [PubMed: 19056602]

117. Nedeltcheva AV, Kilkus JM, Imperial J, Schoeller DA, Penev PD. Insufficient sleep undermines dietary efforts to reduce adiposity. Ann Intern Med. 2010; 153:435-441. [PubMed: 20921542]

118. Nena E, et al. Reduction of serum retinol-binding protein-4 levels in nondiabetic obstructive sleep apnea patients under continuous positive airway pressure treatment. Respiration. 2010; 80:517523. [PubMed: 20224248]

119. Nielsen LS, Danielsen KV, Sorensen TI. Short sleep duration as a possible cause of obesity: critical analysis of the epidemiological evidence. Obes Rev. 2011; 12:78-92. [PubMed: 20345429]

120. Nishiura C, Hashimoto H. A 4-year study of the association between short sleep duration and change in body mass index in Japanese male workers. J Epidemiol. 2010; 20:385-390. [PubMed: 20699599]

121. Oktay B, Akbal E, Firat H, Ardiç S, Kizilgun M. CPAP treatment in the coexistence of obstructive sleep apnea syndrome and metabolic syndrome, results of one year follow up. Acta Clin Belg. 2009; 64:329-334. [PubMed: 19810420]

122. Omisade A, Buxton OM, Rusak B. Impact of acute sleep restriction on cortisol and leptin levels in young women. Physiol Behav. 2010; 99:651-656. [PubMed: 20138072]

123. Palmer ND, et al. Genetic mapping of disposition index and acute insulin response loci on chromosome 11q. The Insulin Resistance Atherosclerosis Study (IRAS) Family Study. Diabetes. 2006; 55:911-918. [PubMed: 16567510]

124. Patel SR, Hu FB. Short sleep duration and weight gain: a systematic review. Obesity (Silver Spring, Md). 2008; 16:643-653.

125. Patel SR, et al. The association between sleep duration and obesity in older adults. Int J Obes. 2008; 32:1825-1834.

126. Pejovic S, et al. Leptin and hunger levels in young healthy adults after one night of sleep loss. J Sleep Res. 2010; 19:552-558. [PubMed: 20545838]

127. Peters A. The selfish brain: competition for energy resources. Am J Hum Biol. 2011; 23:29-34. [PubMed: 21080380]

128. Petrie JR, Pearson ER, Sutherland C. Implications of genome wide association studies for the understanding of type 2 diabetes pathophysiology. Biochem Pharmacol. 2011; 81:471-477. [PubMed: 21111713]

129. Plat L, et al. Effects of morning cortisol elevation on insulin secretion and glucose regulation in humans. Am J Physiol. 1996; 270:E36-E42. [PubMed: 8772471]

130. Plat L, et al. Metabolic effects of short-term elevations of plasma cortisol are more pronounced in the evening than in the morning. J Clin Endocrinol Metabol. 1999; 84:3082-3092.

131. Punjabi NM, et al. Sleep-disordered breathing, glucose intolerance, and insulin resistance: the Sleep Heart Health Study. Am J Epidemiol. 2004; 160:521-530. [PubMed: 15353412] 
132. Raynor HA, Wing RR. Package unit size and amount of food: do both influence intake? Obesity (Silver Spring Md). 2007; 15:2311-2319.

133. Rechtschaffen A, Bergmann BM. Sleep deprivation in the rat by the disk-over-water method. Behav Brain Res. 1995; 69:55-63. [PubMed: 7546318]

134. Resnick HE, et al. Diabetes and sleep disturbances: findings from the Sleep Heart Health Study. Diabetes Care. 2003; 26:702-709. [PubMed: 12610025]

135. Rexrode KM, et al. A prospective study of body mass index, weight change, and risk of stroke in women. JAMA. 1997; 277:1539-1545. [PubMed: 9153368]

136. Rolls A, Borg J Schaich, De Lecea L. Sleep and metabolism: role of hypothalamic neuronal circuitry. Best Pract Res Clin Endocrinol Metab. 2010; 24:817-828. [PubMed: 21112028]

137. Ryden L, et al. Guidelines on diabetes, pre-diabetes, and cardiovascular diseases: executive summary. The Task Force on Diabetes and Cardiovascular Diseases of the European Society of Cardiology (ESC) and of the European Association for the Study of Diabetes (EASD). Eur Heart J. 2007; 28:88-136. [PubMed: 17220161]

138. Saarelainen S, Lahtela J, Kallonen E. Effect of nasal CPAP treatment on insulin sensitivity and plasma leptin. J Sleep Res. 1997; 6:146-147. [PubMed: 9377535]

139. Sakurai T. The neural circuit of orexin (hypocretin): maintaining sleep and wakefulness. Nat Rev Neurosci. 2007; 8:171-181. [PubMed: 17299454]

140. Samuel VT, Petersen KF, Shulman GI. Lipid-induced insulin resistance: unravelling the mechanism. Lancet. 2010; 375:2267-2277. [PubMed: 20609972]

141. Sanders, M. Sleep breathing disorders. In: Kryger, M.; Roth, T.; Dement, WC., editors. Principles and practice of sleep medicine. Saunders; Philadelphia: 2005. p. 969-1157.

142. Schahin SP, et al. Long-term improvement of insulin sensitivity during CPAP therapy in the obstructive sleep apnoea syndrome. Med Sci Mon. 2008; 14:CR117-CR121.

143. Schmid SM, et al. Sleep loss alters basal metabolic hormone secretion and modulates the dynamic counterregulatory response to hypoglycemia. J Clin Endocrinol Metabol. 2007; 92:3044-3051.

144. Schmid SM, Hallschmid M, Jauch-Chara K, Born J, Schultes B. A single night of sleep deprivation increases ghrelin levels and feelings of hunger in normal-weight healthy men. J Sleep Res. 2008; 17:331-334. [PubMed: 18564298]

145. Schmid SM, Jauch-Chara K, Hallschmid M, Schultes B. Mild sleep restriction acutely reduces plasma glucagon levels in healthy men. J Clin Endocrinol Metabol. 2009; 94:5169-5173.

146. Schmid SM, et al. Short-term sleep loss decreases physical activity under free-living conditions but does not increase food intake under time-deprived laboratory conditions in healthy men. Am J Clin Nutr. 2009; 90:1476-1482. [PubMed: 19846546]

147. Schmid SM, et al. Disturbed glucoregulatory response to food intake after moderate sleep restriction. Sleep. 2011; 34:371-377. [PubMed: 21358855]

148. Schoeller DA, Cella LK, Sinha MK, Caro JF. Entrainment of the diurnal rhythm of plasma leptin to meal timing. J Clin Invest. 1997; 100:1882-1887. [PubMed: 9312190]

149. Schuessler P, et al. Nocturnal ghrelin levels-relationship to sleep EEG, the levels of growth hormone, ACTH and cortisol —and gender differences. J Sleep Res. 2005; 14:329-336. [PubMed: 16364133]

150. Seegers V, et al. Short sleep duration and body mass index: a prospective longitudinal study in preadolescence. Am J Epidemiol. 2011; 173:621-629. [PubMed: 21303806]

151. Simon C, Brandenberger G, Follenius M. Ultradian oscillations of plasma glucose, insulin, and Cpeptide in man during continuous enteral nutrition. J Clin Endocrinol Metabol. 1987; 64:669_ 674.

152. Simon C, Brandenberger G, Saini J, Ehrhart J, Follenius M. Slow oscillations of plasma glucose and insulin secretion rate are amplified during sleep in humans under continuous enteral nutrition. Sleep. 1994; 17:333-338. [PubMed: 7973317]

153. Simon C, Gronfier C, Schlienger JL, Brandenberger G. Circadian and ultradian variations of leptin in normal man under continuous enteral nutrition: relationship to sleep and body temperature. J Clin Endocrinol Metabol. 1998; 83:1893-1899. 
154. Simpson NS, Banks S, Dinges DF. Sleep restriction is associated with increased morning plasma leptin concentrations, especially in women. Biol Res Nurs. 2010; 12:47-53. [PubMed: 20453022]

155. Sinton CM, Fitch TE, Gershenfeld HK. The effects of leptin on REM sleep and slow wave delta in rats are reversed by food deprivation. J Sleep Res. 1999; 8:197-203. [PubMed: 10476006]

156. Smurra M, et al. CPAP treatment does not affect glucose-insulin metabolism in sleep apneic patients. Sleep Med. 2001; 2:207-213. [PubMed: 11311683]

157. Somers VK, Dyken ME, Clary MP, Abboud FM. Sympathetic neural mechanisms in obstructive sleep apnea. J Clin Invest. 1995; 96:1897. [PubMed: 7560081]

158. Sorensen TI. Conference on "Multidisciplinary approaches to nutritional problems". Symposium on "Diabetes and health". Challenges in the study of causation of obesity. Proc Nutr Soc. 2009; 68:43-54. [PubMed: 19079823]

159. Spiegel K, Leproult R, Van Cauter E. Impact of sleep debt on metabolic and endocrine function. Lancet. 1999; 354:1435-1439. [PubMed: 10543671]

160. Spiegel K, et al. Adaptation of the 24-h growth hormone profile to a state of sleep debt. Am J Physiol. 2000; 279:R874-R883.

161. Spiegel K, et al. Leptin levels are dependent on sleep duration: relationships with sympathovagal balance, carbohydrate regulation, cortisol, and thyrotropin. J Clin Endocrinol Metabol. 2004; 89:5762-5771.

162. Spiegel K, Tasali E, Penev P, Van Cauter E. Sleep curtailment in healthy young men is associated with decreased leptin levels, elevated ghrelin levels, and increased hunger and appetite. Ann Intern Med. 2004; 141:846-850. [PubMed: 15583226]

163. Spiegel, K., et al. The 24-hour profile of plasma PYY levels in normal adults: relationships with sleep, meal intake and ghrelin levels. The Endocrine Society's 87th Annual Meeting Abstract number OR8-3; San Diego, CA, USA. June 2005; 2005. p. 82-83.

164. Spiegel K, Knutson K, Leproult R, Tasali E, Van Cauter E. Sleep loss: a novel risk factor for insulin resistance and type 2 diabetes. J Appl Physiol. 2005; 99:2008-2019. [PubMed: 16227462]

165. Spiegel K, Tasali E, Leproult R, Van Cauter E. Effects of poor and short sleep on glucose metabolism and obesity risk. Nat Rev. 2009; 5:253-261.

166. Spiegel K, Tasali E, Leproult R, Scherberg N, Van Cauter E. Twenty-four-hour profiles of acylated and total ghrelin: relationship with glucose levels and impact of time of day and sleep. $\mathrm{J}$ Clin Endocrinol Metabol. 2011; 96:486-493.

167. Stamatakis KA, Punjabi NM. Effects of sleep fragmentation on glucose metabolism in normal subjects. Chest. 2010; 137:95-101. [PubMed: 19542260]

168. Steiger A. Sleep and endocrinology. J Intern Med. 2003; 254:13-22. [PubMed: 12823639]

169. Steiropoulos P, et al. Markers of glycemic control and insulin resistance in non-diabetic patients with obstructive sleep apnea hypopnea syndrome: does adherence to CPAP treatment improve glycemic control? Sleep Med. 2009; 10:887-891. [PubMed: 19231280]

170. St-Onge MP, et al. Short sleep duration increases energy intakes but does not change energy expenditure in normal-weight individuals. Am J Clin Nutr. 2011; 94:410-416. [PubMed: 21715510]

171. Stoohs RA, Facchini FS, Philip P, Valencia-Flores M, Guilleminault C. Selected cardiovascular risk factors in patients with obstructive sleep apnea: effect of nasal continuous positive airway pressure (n-CPAP). Sleep. 1993; 16:S141-S142. [PubMed: 8178008]

172. Szentirmai E, Hajdu I, Obal F Jr, Krueger JM. Ghrelin-induced sleep responses in ad libitum fed and food-restricted rats. Brain Res. 2006; 1088:131-140. [PubMed: 16631138]

173. Szentirmai E, Kapas L, Krueger JM. Ghrelin microinjection into forebrain sites induces wakefulness and feeding in rats. Am J Physiol. 2007; 292:R575-R585.

174. Taheri S, Lin L, Austin D, Young T, Mignot E. Short sleep duration is associated with reduced leptin, elevated ghrelin, and increased body mass index. PLoS Med. 2004; 1:e62. [PubMed: 15602591]

175. Tasali E, Ip MS. Obstructive sleep apnea and metabolic syndrome: alterations in glucose metabolism and inflammation. Proc Am Thorac Soc. 2008; 5:207-217. [PubMed: 18250214] 
176. Tasali E, Leproult R, Ehrmann DA, Van Cauter E. Slow-wave sleep and the risk of type 2 diabetes in humans. Proc Natl Acad Sci USA. 2008; 105:1044-1049. [PubMed: 18172212]

177. Tasali E, Mokhlesi B, Van Cauter E. Obstructive sleep apnea and type 2 diabetes: interacting epidemics. Chest. 2008; 133:496-506. [PubMed: 18252916]

178. Tasali E, Leproult R, Spiegel K. Reduced sleep duration or quality: relationships with insulin resistance and type 2 diabetes. Prog Cardiovasc Dis. 2009; 51:381-391. [PubMed: 19249444]

179. Tasali, E.; Broussard, J.; Day, A.; Kilkus, J.; Van Cauter, E. Sleep curtailment in healthy young adults is associated with increased ad lib food intake. 23rd Annual Meeting of the Associated Professional Sleep Societies; Seattle, WA, USA. 2009. p. A131-A131.S Abstract 394

180. Tasali E, Chapotot F, Leproult R, Whitmore H, Ehrmann DA. Treatment of obstructive sleep apnea improves cardio-metabolic function in young obese women with polycystic ovary syndrome. J Clin Endocrinol Metabol. 2011; 96:365.

181. Teramoto S, et al. Cardiovascular and metabolic effects of CPAP in obese obstructive sleep apnoea patients. Eur Respir J. 2008; 31:223. [PubMed: 18166604]

182. Theorell-Haglow J, Berne C, Janson C, Sahlin C, Lindberg E. Associations between short sleep duration and central obesity in women. Sleep. 2010; 33:593-598. [PubMed: 20469801]

183. Thomas M, et al. Neural basis of alertness and cognitive performance impairments during sleepiness. I. Effects of $24 \mathrm{~h}$ of sleep deprivation on waking human regional brain activity. J Sleep Res. 2000; 9:335-352. [PubMed: 11123521]

184. Tomfohr LM, Edwards KM, Dimsdale JE. Is obstructive sleep apnea associated with cortisol levels? A systematic review of the research evidence. Sleep Med Rev. 2011 doi:10.1016/j.smrv. 2011.05.003.

185. Trenell MI, et al. Influence of constant positive airway pressure therapy on lipid storage, muscle metabolism and insulin action in obese patients with severe obstructive sleep apnoea syndrome. Diabetes Obes Metab. 2007; 9:679-687. [PubMed: 17697060]

186. Van Cauter, E. Endocrine physiology. In: Kryger, M.; Roth, T.; Dement, WC., editors. Principles and practice of sleep medicine. 4th edn. Elsevier-Saunders; Philadelphia: 2005.

187. Van Cauter E, et al. Modulation of glucose regulation and insulin secretion by circadian rhythmicity and sleep. J Clin Invest. 1991; 88:934-942. [PubMed: 1885778]

188. Van Cauter E, et al. A quantitative estimation of growth hormone secretion in normal man: reproducibility and relation to sleep and time of day. J Clin Endocrinol Metabol. 1992; 74:14411450 .

189. Van Cauter E, Polonsky KS, Scheen AJ. Roles of circadian rhythmicity and sleep in human glucose regulation. Endocr Rev. 1997; 18:716-738. [PubMed: 9331550]

190. van den Berg JF, et al. Actigraphic sleep duration and fragmentation are related to obesity in the elderly: the Rotterdam Study. Int J Obes. 2008; 32:1083-1090.

191. van der Lely AJ. Ghrelin and new metabolic frontiers. Horm Res. 2009; 71(Suppl 1):129-133. [PubMed: 19153523]

192. van der Lely AJ, Tschop M, Heiman ML, Ghigo E. Biological, physiological, pathophysiological, and pharmacological aspects of ghrelin. Endocr Rev. 2004; 25:426-457. [PubMed: 15180951]

193. van Dijk G. The role of leptin in the regulation of energy balance and adiposity. $J$ Neuroendocrinol. 2001; 13:913-921. [PubMed: 11679060]

194. van Leeuwen WM, et al. Prolonged sleep restriction affects glucose metabolism in healthy young men. Int J Endocrinol. 2010; 2010:108641. [PubMed: 20414467]

195. VanHelder T, Symons JD, Radomski MW. Effects of sleep deprivation and exercise on glucose tolerance. Aviat Space Environ Med. 1993; 64:487-492. [PubMed: 8338493]

196. Vgontzas AN, Bixler EO. Short sleep and obesity: are poor sleep, chronic stress, and unhealthy behaviors the link? Sleep. 2008; 31:1203. [PubMed: 18788643]

197. Vgontzas A, et al. Hypothalamic-pituitary-adrenal axis activity in obese men with and without sleep apnea: effects of continuous positive airway pressure therapy. J Clin Endocrinol Metabol. 2007; 92:4199.

198. Vgontzas AN, et al. Short sleep duration and obesity: the role of emotional stress and sleep disturbances. Int J Obes. 2008; 32:801-809. 
199. Vgontzas A, Zoumakis E, Bixler E, Lin H. Selective effects of CPAP on sleep apnoea associated manifestations. Eur J Clin Invest. 2008; 38:585-595. [PubMed: 18627419]

200. Vondra K, et al. Effects of sleep deprivation on the activity of selected metabolic enzymes in skeletal muscle. Eur J Appl Physiol Occup Physiol. 1981; 47:41-46. [PubMed: 6795038]

201. Wallace TM, Levy JC, Matthews DR. Use and abuse of HOMA modeling. Diabetes Care. 2004; 27:1487. [PubMed: 15161807]

202. Watanabe M, Kikuchi H, Tanaka K, Takahashi M. Association of short sleep duration with weight gain and obesity at 1-year follow-up: a large-scale prospective study. Sleep. 2010; 33:161-167. [PubMed: 20175399]

203. Weaver TE, et al. An instrument to measure functional status outcomes for disorders of excessive sleepiness. Sleep. 1997; 20:835-843. [PubMed: 9415942]

204. Wehrens SM, Hampton SM, Finn RE, Skene DJ. Effect of total sleep deprivation on postprandial metabolic and insulin responses in shift workers and non-shift workers. J Endocrinol. 2010; 206:205-215. [PubMed: 20479040]

205. Wei CY, et al. Effects of continuous positive airway pressure upon $24 \mathrm{~h}$ changes of blood glucose level in patients with obstructive sleep apnea hypopnea syndrome and type 2 diabetes. Zonghua Yi Xue Yi Chuan Xue Za Zi. 2009; 89:2686-2689.

206. West SD, Nicoll DJ, Wallace TM, Matthews DR, Stradling JR. Effect of CPAP on insulin resistance and HbA1c in men with obstructive sleep apnoea and type 2 diabetes. Thorax. 2007; 62:969. [PubMed: 17557769]

207. White DP, Weil JV, Zwillich CW. Metabolic rate and breathing during sleep. J Appl Physiol. 1985; 59:384-391. [PubMed: 3928586]

208. Willett WC, et al. Weight, weight change, and coronary heart disease in women. Risk within the 'normal' weight range. JAMA. 1995; 273:461-465. [PubMed: 7654270]

209. Williams CJ, Hu FB, Patel SR, Mantzoros CS. Sleep duration and snoring in relation to biomarkers of cardiovascular disease risk among women with type 2 diabetes. Diabetes Care. 2007; 30:1233-1240. [PubMed: 17322482]

210. Wilson DF. Measuring in vivo metabolite levels in brain. Sleep. 2011; 34:837. author reply 841833. [PubMed: 21731131]

211. Wong-Riley M. What is the meaning of the ATP surge during sleep? Sleep. 2011; 34:833-834. author reply 841-833. [PubMed: 21731129]

212. Wu MF, John J, Maidment N, Lam HA, Siegel JM. Hypocretin release in normal and narcoleptic dogs after food and sleep deprivation, eating, and movement. Am J Physiol. 2002; 283:R1079R1086.

213. Xiang AH, et al. Effect of pioglitazone on pancreatic beta-cell function and diabetes risk in Hispanic women with prior gestational diabetes. Diabetes. 2006; 55:517-522. [PubMed: 16443789]

214. Yki-Järvinen H. Thiazolidinediones. N Eng J Med. 2004; 351:1106-1118.

215. Young T, Peppard PE, Taheri S. Excess weight and sleep-disordered breathing. J Appl Physiol. 2005; 99:1592-1599. [PubMed: 16160020]

216. Zeitzer JM, Buckmaster CL, Lyons DM, Mignot E. Increasing length of wakefulness and modulation of hypocretin-1 in the wake-consolidated squirrel monkey. Am J Physiol. 2007; 293:R1736-R1742.

217. Zielinski MR, Kline CE, Kripke DF, Bogan RK, Youngstedt SD. No effect of 8-week time in bed restriction on glucose tolerance in older long sleepers. J Sleep Res. 2008; 17:412-419. [PubMed: 18691360] 
a

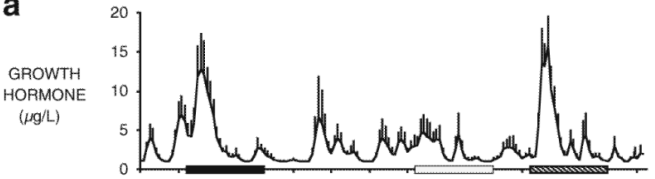

b

b

CORTISOL
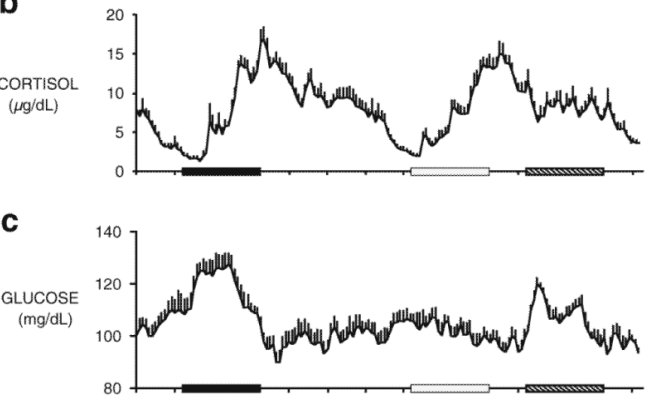

d

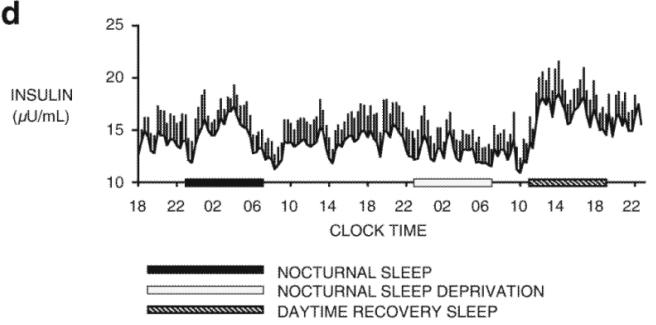

Fig. 1.

From top to bottom Mean (+SEM) profiles of a growth hormone, $\mathbf{b}$ cortisol, $\mathbf{c}$ glucose, and $\mathbf{d}$ insulin in eight healthy young men studied during a 53-h period including8hof nocturnal sleep (black bars), followed by $28 \mathrm{~h}$ of sleep deprivation including a period of nocturnal sleep deprivation (open bars), and $8 \mathrm{~h}$ of daytime recovery sleep (dashed bars). Data were obtained at 20-min intervals under continuous glucose infusion. (adapted from [187]) 


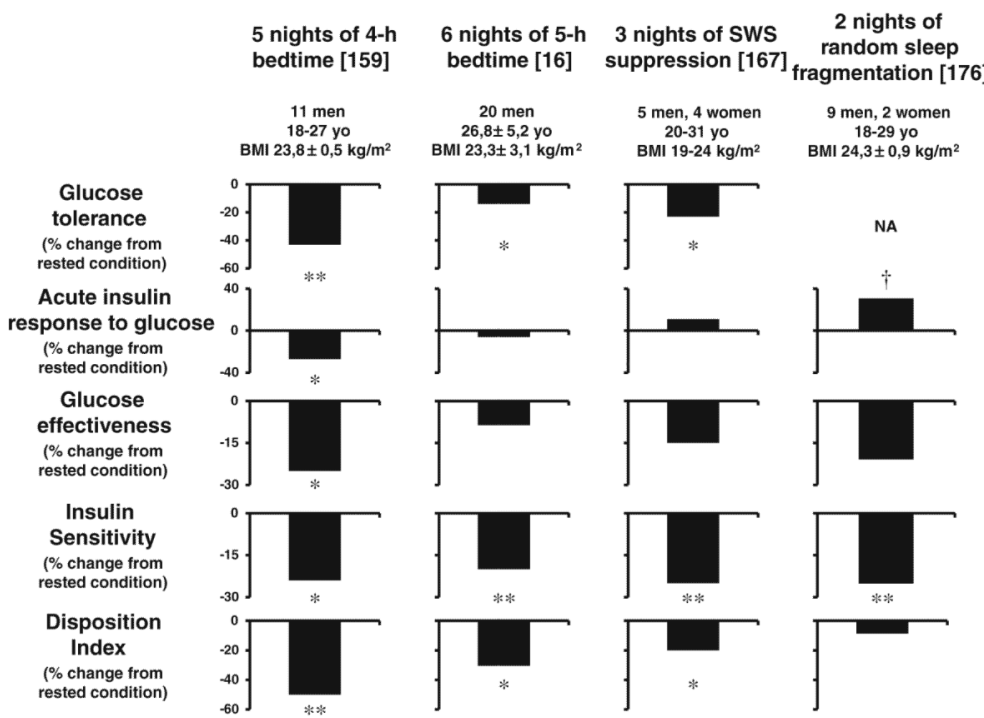

Fig. 2.

Alterations in glucose metabolism assessed by intravenous glucose testing in four wellcontrolled laboratory studies. The two left panels illustrate the effects of reduced sleep duration (adapted from $[16,159]$ ). The two right panels illustrate the effects of disturbed sleep, independently of sleep duration (adapted from $[167,176])$. ** $p<0.01$, ${ }^{*} p<0.05,{ }^{\dagger} p<0.10$ 
a
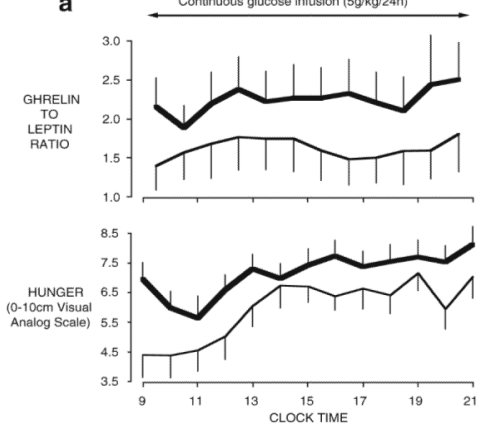

- AFTER 2 DAYS OF 10-H BEDTIMES

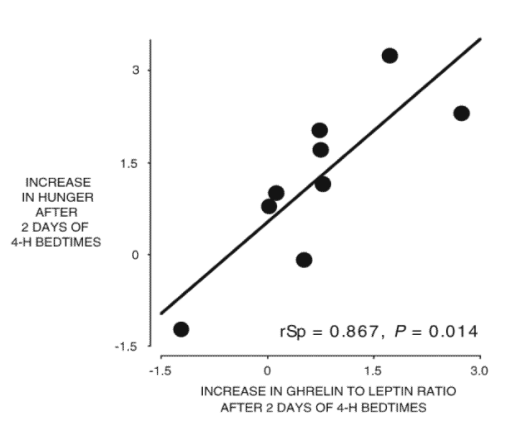

Fig. 3.

a Mean $( \pm$ SEM) daytime of ghrelin/leptin ratio and ratings of hunger obtained in nine young healthy mean under continuous glucose infusion after 2 days with 4-h bedtimes or after 2 days with 10-h bedtimes. b Association between the increase in hunger ratings and the increase in ghrelin/leptin ratio when sleep is restricted as compared to extended 
Table 1

Impact of total (upper panel) and partial sleep deprivation (lower panel) on glucose metabolism

\begin{tabular}{|c|c|c|}
\hline Outcome measure & $\begin{array}{l}\text { Studies with } \\
\text { positive effect } \\
\text { reported }\end{array}$ & $\begin{array}{l}\text { Studies with } \\
\text { no effect } \\
\text { reported }\end{array}$ \\
\hline \multicolumn{3}{|l|}{ Total sleep deprivation } \\
\hline \multicolumn{3}{|l|}{ Increased fasting glucose $\mathrm{e}^{a}$} \\
\hline Number of studies & $1[200]$ & $\begin{array}{c}5[5,86,143, \\
195,204]\end{array}$ \\
\hline Number of subjects & $7 \mathrm{M}$ & $75 \mathrm{M}$ \\
\hline $\begin{array}{l}\text { Duration of forced } \\
\text { wakefulness }\end{array}$ & $120 \mathrm{~h}$ & $24-126 \mathrm{~h}$ \\
\hline \multicolumn{3}{|l|}{ Decreased glucose tolerance $b$} \\
\hline Number of studies & $2[5,86]$ & $2[195,204]$ \\
\hline Number of subjects & $42 \mathrm{M}$ & $23 \mathrm{M}$ \\
\hline $\begin{array}{l}\text { Duration of forced } \\
\text { wakefulness }\end{array}$ & $24-126 \mathrm{~h}$ & $24-60 \mathrm{~h}$ \\
\hline \multicolumn{3}{|l|}{ Insulin resistance ${ }^{c}$} \\
\hline Number of studies & $3[5,57,195]$ & $2[143,204]$ \\
\hline Number of subjects & $38(31 \mathrm{M}, 7 \mathrm{~F})$ & $23 \mathrm{M}$ \\
\hline $\begin{array}{l}\text { Duration of forced } \\
\text { wakefulness }\end{array}$ & $24-60 \mathrm{~h}$ & 24 \\
\hline \multicolumn{3}{|l|}{ Beta-cell dysfunction ${ }^{d}$} \\
\hline Number of studies & $1[5]$ & - \\
\hline Number of subjects & $14 \mathrm{M}$ & \\
\hline $\begin{array}{l}\text { Duration of forced } \\
\text { wakefulness }\end{array}$ & $24 \mathrm{~h}$ & \\
\hline \multicolumn{3}{|l|}{ Altered alpha-cell function ${ }^{e}$} \\
\hline Number of studies & $1[143]$ & - \\
\hline Number of subjects & $10 \mathrm{M}$ & \\
\hline $\begin{array}{l}\text { Duration of forced } \\
\text { wakefulness }\end{array}$ & $24 \mathrm{~h}$ & \\
\hline \multicolumn{3}{|l|}{ Partial sleep deprivation } \\
\hline \multicolumn{3}{|l|}{ Decreased glucose tolerance $f$} \\
\hline Number of studies & $\begin{array}{c}6[16,91,115, \\
147,159,164]\end{array}$ & $2[11,217]$ \\
\hline Number of subjects & $81(74 \mathrm{M}, 7 \mathrm{~F})$ & $36(22 \mathrm{M}, 14 \mathrm{~F})$ \\
\hline Average TIB duration (range) & $5 \mathrm{~h}(4-5.5)$ & $7 \mathrm{~h}(5.25-7.7 \mathrm{~h})$ \\
\hline $\begin{array}{l}\text { Average duration of } \\
\text { sleep restriction (range) }\end{array}$ & 6 nights (1-14) & $\begin{array}{l}1 \text { night- } \\
8 \text { weeks }\end{array}$ \\
\hline \multicolumn{3}{|l|}{ Insulin resistance $g$} \\
\hline Number of studies & $\begin{array}{c}7[16,41,91,115 \\
\quad 147,159,194]\end{array}$ & $3[11,145,217]$ \\
\hline Number of subjects & $93(82 \mathrm{M}, 11 \mathrm{~F})$ & $46(16 \mathrm{M}, 30 \mathrm{~F})$ \\
\hline Average TIB duration (range) & $5 \mathrm{~h}(4-5.5)$ & $7.5 \mathrm{~h}(4-7.7)$ \\
\hline
\end{tabular}




\begin{tabular}{|c|c|c|}
\hline Outcome measure & $\begin{array}{l}\text { Studies with } \\
\text { positive effect } \\
\text { reported }\end{array}$ & $\begin{array}{l}\text { Studies with } \\
\text { no effect } \\
\text { reported }\end{array}$ \\
\hline $\begin{array}{l}\text { Average duration of } \\
\text { sleep restriction (range) }\end{array}$ & 6 nights (1-14) & $\begin{array}{l}1 \text { night- } \\
8 \text { weeks }\end{array}$ \\
\hline \multicolumn{3}{|l|}{ Beta-cell dysfunction $h$} \\
\hline Number of studies & $\begin{array}{c}5[16,91,115, \\
159,164]\end{array}$ & $2[11,147]$ \\
\hline Number of subjects & $29(15 \mathrm{M}, 14 \mathrm{~F})$ & $14 \mathrm{~F}$ \\
\hline Average TIB duration (range) & $5 \mathrm{~h}(4.25-5.75)$ & $5.75 \mathrm{~h}$ \\
\hline $\begin{array}{l}\text { Average duration of } \\
\text { sleep restriction (range) }\end{array}$ & 3 days (2-4) & 4 nights \\
\hline \multicolumn{3}{|l|}{ Altered alpha-cell function $i$} \\
\hline Number of studies & $2[145,147]$ & - \\
\hline Number of subjects & $25 \mathrm{M}$ & \\
\hline Average TIB duration (range) & $4.4 \mathrm{~h}(4.25-4.5 \mathrm{~h})$ & \\
\hline $\begin{array}{l}\text { Average duration of } \\
\text { sleep restriction (range) }\end{array}$ & 1.5 nights (1-2) & \\
\hline
\end{tabular}

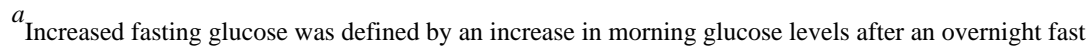

$b$ Decreased glucose tolerance was defined by an increased response of glucose to OGTT or to a standardized breakfast

${ }^{c}$ Insulin resistance was defined by an increased insulin response to OGTT or by increased steady-state glucose levels during an insulin suppression test modified with octreotide

$d$ Beta-cell dysfunction was defined by increased glucose levels and lack of concomitant compensatory increase in insulin response to standardized breakfast

${ }^{e}$ Altered alpha-cell function was defined by an increased relative response of glucagon during a stepwise hypoglycemic clamp

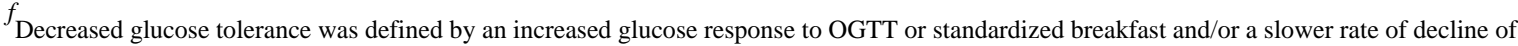
glucose levels during ivGTT or increased glucose levels during constant-rate i.v. glucose infusion

${ }^{g}$ Insulin resistance was defined by decreased SI assessed by HEC, or decreased SI assessed by ivGTT, or increased insulin response to OGTT or standardized breakfast in the face of similar or reduced glucose tolerance, or increased HOMA-IR index, or increased fasting insulin/glucose ratio

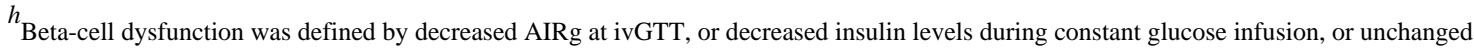
insulin response in the face of increased glucose response to standardized breakfast

${ }^{i}$ Altered alpha-cell function was defined by a decreased response of glucagon during a stepwise hypoglycemic clamp or after a standardized breakfast

OGTT Oral glucose tolerance test, ivGTT intravenous glucose tolerance test, HEC hyperinsulinemic euglycemic clamp, HOMA-IR homeostatic model assessment- insulin resistance, $A I R g$ acute insulin response to glucose 


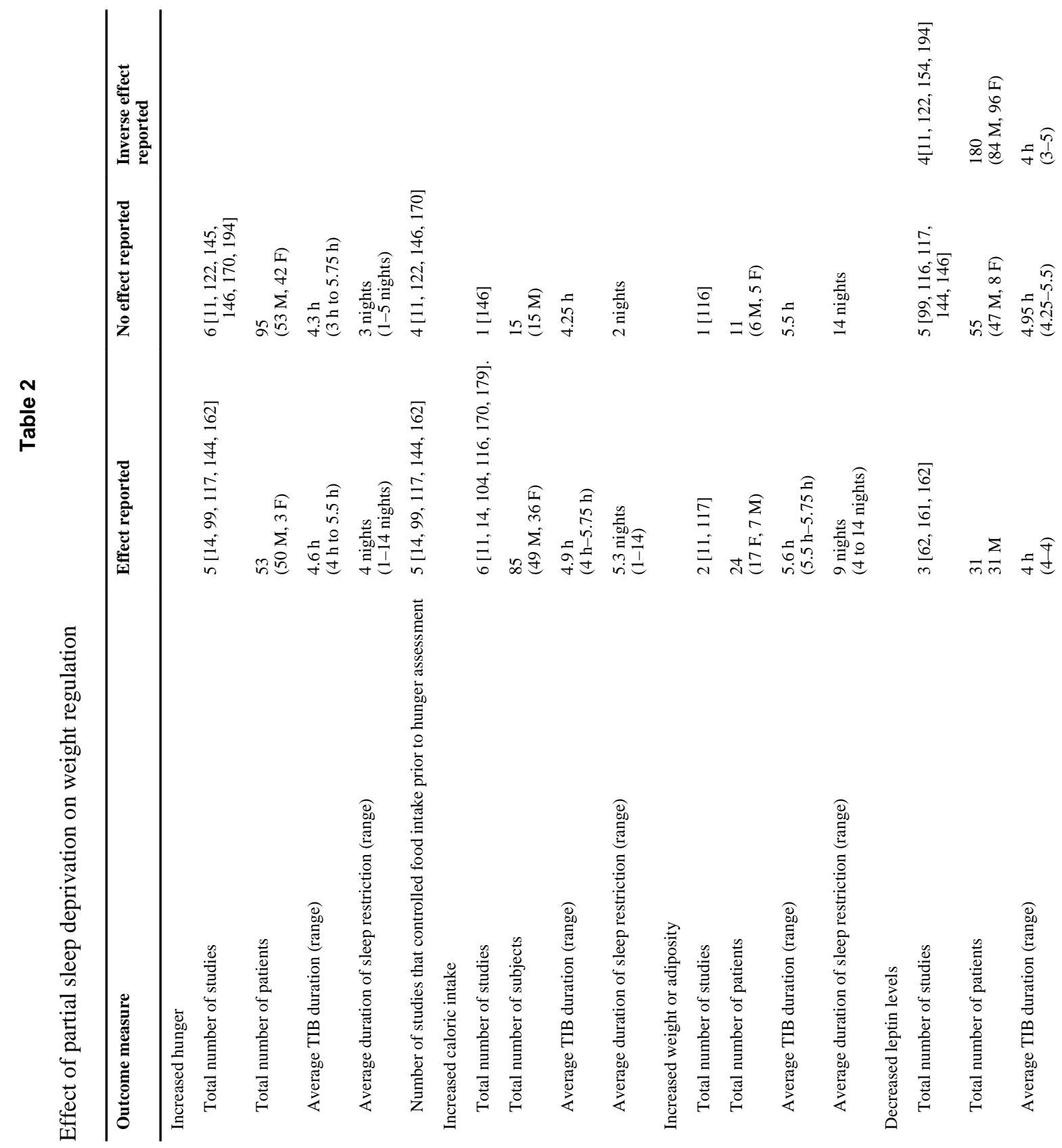




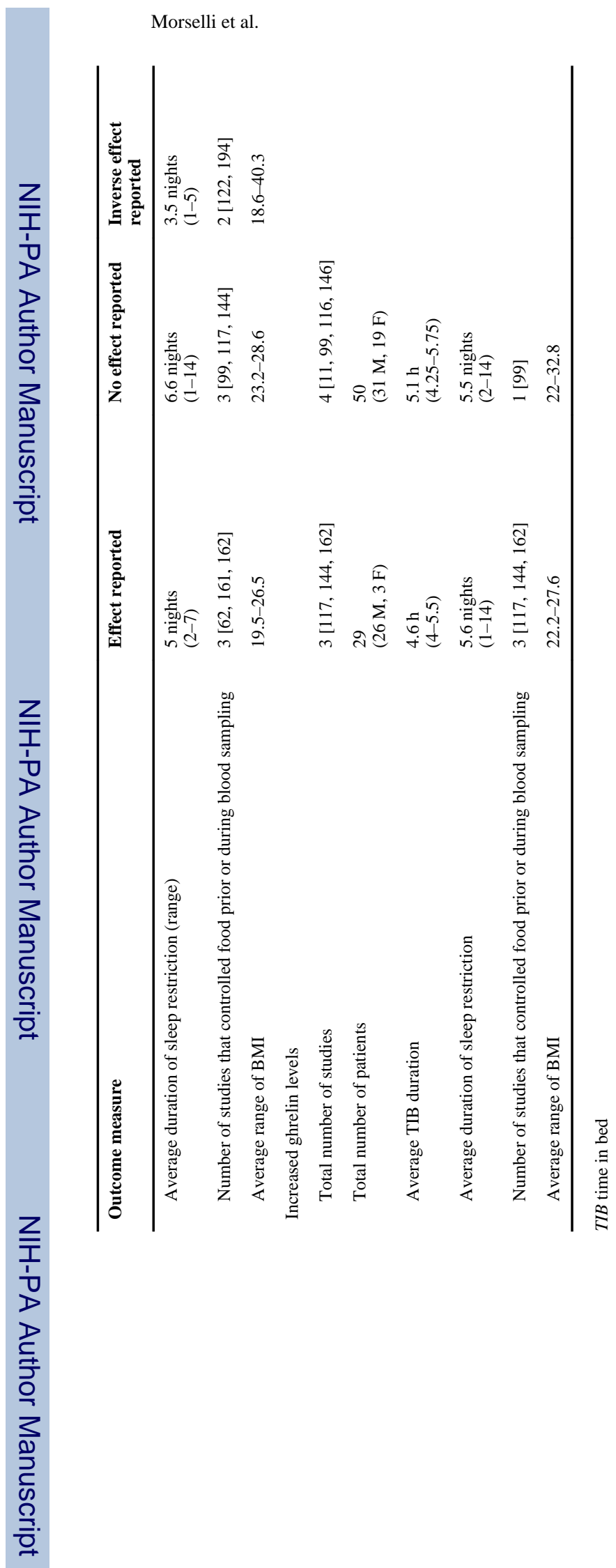

Pflugers Arch. Author manuscript; available in PMC 2013 January 1. 

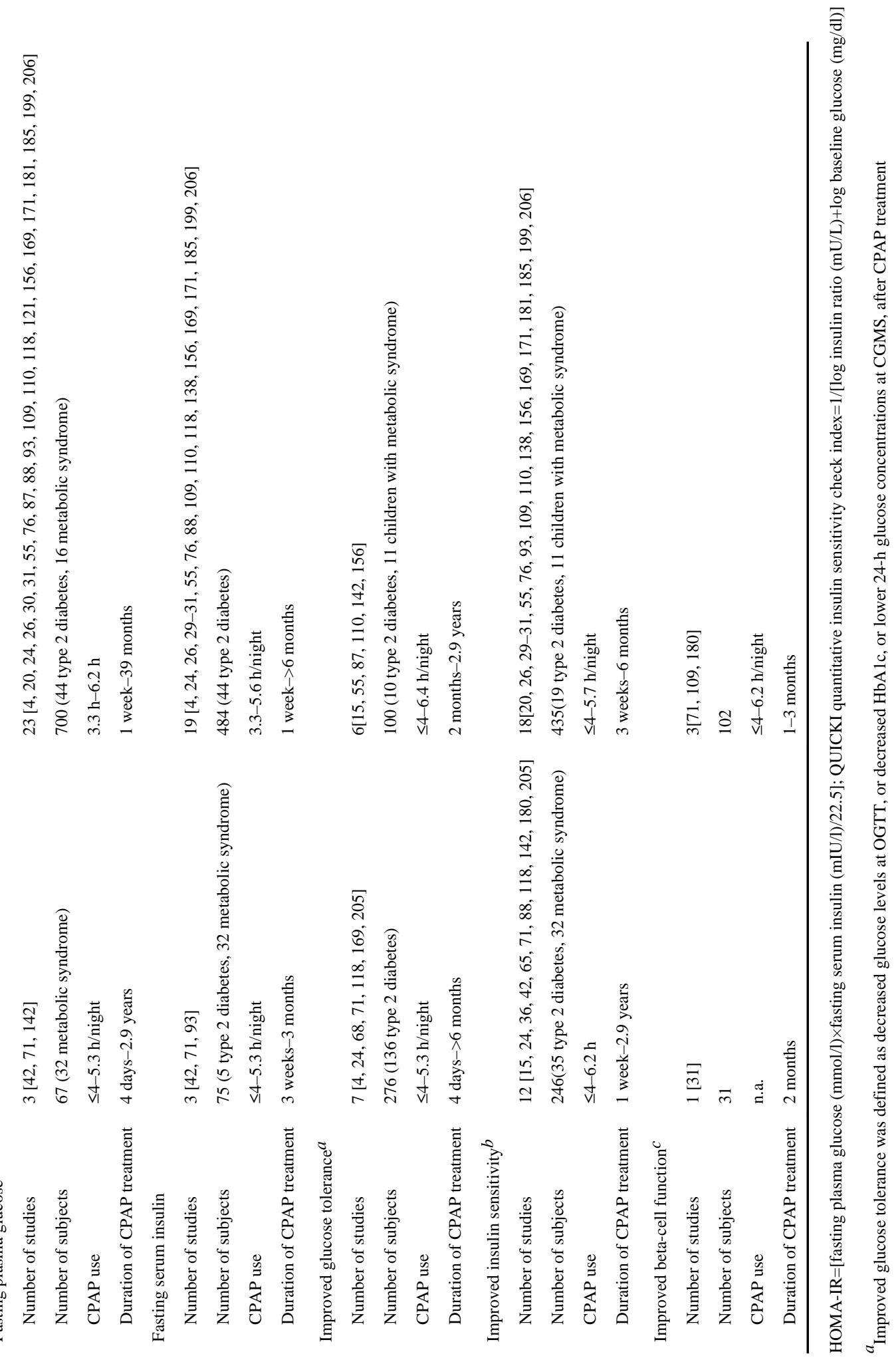

Pflugers Arch. Author manuscript; available in PMC 2013 January 1. 


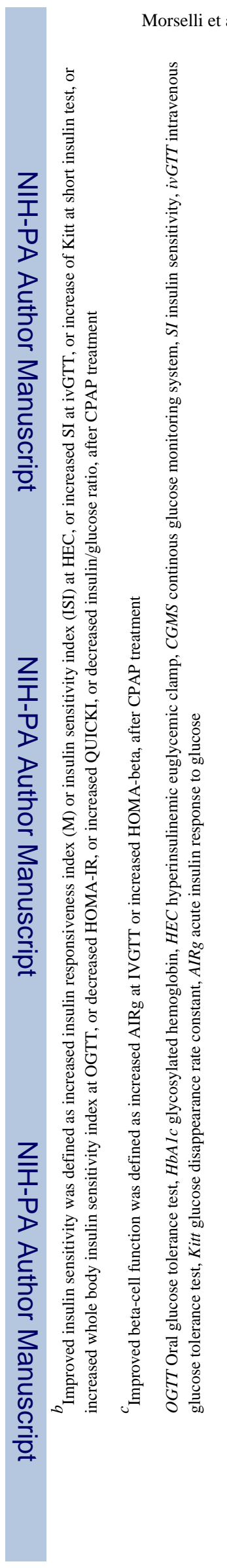

Page 36

Pflugers Arch. Author manuscript; available in PMC 2013 January 1. 